Article

\title{
Agricultural Monitoring in Northeastern Ontario, Canada, Using Multi-Temporal Polarimetric RADARSAT-2 Data
}

\author{
Jeffrey W. Cable ${ }^{1}$, John M. Kovacs ${ }^{1}{ }^{*}$, Xianfeng Jiao ${ }^{1}$ and Jiali Shang ${ }^{2}$
}

1 Department of Geography, Nipissing University, 100 College Drive, North Bay ON P1B 8L7, Canada; E-Mails: j.w.cable@ hotmail.com (J.W.C.); xianfeng.jiao@nrcan-rncan.gc.ca (X.J.)

2 Science and Technology Branch, Agriculture and Agri-Food Canada, 960 Carling Ave, Ottawa ON K1A 0C6, Canada; E-Mail: jiali.shang@agr.gc.ca

* Author to whom correspondence should be addressed; E-Mail: johnmk@ @ipissingu.ca; Tel.: +1-705-474-3450 (ext. 4336); Fax: +1-705-474-1947.

Received: 26 December 2013; in revised form: 21 February 2014 / Accepted: 3 March 2014 / Published: 17 March 2014

\begin{abstract}
The purpose of this research is to analyze how changes in acquisition time and incidence angle affect various C-band synthetic aperture radar (SAR) polarimetric intensities, co-polarized phase information, polarimetric response plots and decomposition parameters for various crops typical of Northern Ontario, Canada. We examine how these parameters may be used to monitor the growth stages of five common cash crops, namely, barley (Hordeum vulgare), canola (Brassica napus), oat (Avena sativa), soybean (Glycine max) and wheat (Triticum spp.). In total, nine RADARSAT-2 polarimetric images were analyzed across a 14-week period beginning in June and ending in September 2011 using two incidence angles of approximately $26^{\circ}$ and $41^{\circ}$. As expected, the backscatter intensities for all targets were found to show a higher response when acquired at the steeper incidence angle $\left(26^{\circ}\right)$. All cash crop targets showed a rise and fall in backscatter response over the course of the growing season, coinciding with changing growth stages. Slight phase differences were observed for cereal crops, possibly due to one of the polarizations penetrating between the rows allowing double-bounce to occur. The polarimetric response plots and decompositions offered insight into the scattering mechanisms of each crop type, generally showing an increase in volume scattering as the crops reached maturity. Specifically, the contributions of the crops increased towards the volume scattering component and zones 4 and 2, as the crops matured in regards to the Freeman-Durden and Cloude-Pottier decompositions respectively. Overall, soybean and canola showed a more similar response in comparison to the cereal cash crops. Although
\end{abstract}


the study focused on Northern Ontario, it is anticipated that these results would be relevant in investigations of multi-temporal RADARSAT-2 for agricultural zones with similar crop types.

Keywords: RADARSAT-2; polarimetric SAR; incidence angle; monitoring; agriculture; Northern Ontario; backscatter intensity; co-polarized phase difference; polarimetric response plots; decomposition parameters

\section{Introduction}

The agricultural sector is a key component of the Canadian economy providing one in eight jobs and accounting for more than 8\% of the country's total Gross Domestic Product (GDP) in 2011 [1]. Globally, Canada was the sixth largest exporter (3.3\%) of agricultural products in 2011. However, as the global demand for agricultural products rises, producers are required to find new ways to increase productivity while decreasing costs. One recent alternative has been the use of precision agriculture techniques which more often than not include the use of georeferenced harvest yield data to identify field variability. Unfortunately, these data are not available until the end of the crop cycle, and thus quick countermeasures are not possible (e.g., variable rate fertilizer). Two of the more important requirements for product estimation are crop identification and crop condition. Unlike conventional optical data, SAR imagery can be collected regardless of time of day and, most importantly for Northern Ontario, regardless of cloud cover. Polarimetric SAR imagery may provide the data necessary to quickly and consistently assess the condition of the crops during the growing season, and consequently, determine whether changes (e.g., additional fertilizer, pesticides) need to be made in order to improve productivity.

It is well documented that the development of crops over time leads to changes in backscatter [2-6]. Moreover, it is suggested that the important scattering mechanisms when dealing with agricultural areas are direct backscatter from bare soil/underlying ground, direct backscatter from the plant components (leaves, stems, fruit), double-bounce backscatter between the soil surface and crop canopy, and in some cases ground-vegetation-ground and multiple scattering mechanisms [2,7]. These scattering types can be heavily influenced by the incidence angle. For many surfaces, the backscatter decreases with an increasing incidence angle as shallow angles result in specular reflection. However, when considering vegetation, a shallow angle may result in diffuse backscatter from the canopy, whereas a steep incidence angle would be more typical of surface scattering from the soil or canopy components [8]. The research suggests that when seeds are still below the surface, the main contributor to a radar response is single-bounce backscatter due to the rough, plowed state of the soil as well as moisture content of the soil [9]. As plant elements emerge and begin to develop, both the co-polarized and cross-polarized backscatter intensities tend to increase. The increase in co-polarized backscatter is due to a combination of single bounce backscatter directly off leaves or stems, etc. and soil-vegetation double-bounce backscatter, whereas the cross-polarized backscatter is amplified by volume scattering influenced by the crop canopy. One way to discriminate between the surface and 
double-bounce is to use the co-polarized phase difference. Both Skriver et al. [2] and McNairn et al. [10] observed that co-polarized phase differences aid in revealing the dominant scattering mechanism for various crop types and growth stages. Specifically, the phase difference observed in these studies is likely due to the delay resulting from the phase in the vegetation canopy for $\mathrm{V}$ polarization being different from that of $\mathrm{H}$ polarization [11]. It has also been shown that polarization responses and decompositions may provide additional information on crop type and growth stage development

Previous literature of polarimetric RADARSAT-2 data has primarily focused on mapping targets with less emphasis on how these targets actually interact with the SAR [12-15]. While the ability to classify targets is essential, literature comparing the nature of $\mathrm{C}$-band polarimetric data with different targets remains limited. Consequently, we believe it is important that analysts understand how polarimetric SAR interacts with targets before attempting complex polarimetric RADARSAT-2 classifications, particularly in Northern Ontario where various targets are more likely to abound in each acquisition. In this investigation, the analysis of the aforementioned parameters will aid in understanding how polarimetric C-band SAR interacts with crop targets and also to describe typical scattering properties for each crop types over the growing season and according to different incidence angles. A continuous time series of polarimetric data will provide a better understanding of how the backscatter response changes throughout the growing season, particularly in Northern Ontario, for the most common cash crop types. For information regarding the response of non-agricultural targets (e.g., forest, urban infrastructure, wetlands) to multi-temporal RADARSAT-2 in this study area, the reader is referred to the complementary study by Cable et al. [16].

\section{Study Area}

The communities of Sturgeon Falls $\left(46^{\circ} 21^{\prime} \mathrm{N}, 79^{\circ} 55^{\prime} \mathrm{W}\right)$ and Verner $\left(46^{\circ} 24^{\prime} \mathrm{N}, 80^{\circ} 7^{\prime} \mathrm{W}\right)$ are located in the municipality of West Nipissing, Ontario, Canada (Figure 1), along the north shore of Lake Nipissing, within the Great Lakes basin. The region is situated within a small clay belt which formed as a result of fine sediment particle deposition that occurred during the last glacial recession when a much larger Lake Nipissing was part of glacial Lake Algonquin [17]. According to Baldwin et al. [18], gleysolic, or clay, soils — which are prominent around the study site - are well suited for agricultural production. Although these soils characteristically have poor drainage, thousands of acres of tile and municipal drainage systems have been installed to maximize soil and crop productivity [19]. Summer growing seasons are typically short (May to September) and warm with ample precipitation for crop production [17]. Improved technology and increased crop demand have encouraged the development of hybrid plants, which are adapted to shorter, cooler growing seasons. This has led to a shift from dairy to cash crop farming in Northern Ontario as the amount of cropland in Southern Ontario decreases due to urban sprawl. The West Nipissing agricultural zone is typical of other Northern Ontario agricultural regions in that the fields are typically dispersed on flat areas surrounded by lakes, wetlands and mixed forests that are more typical of the Canadian Shield where they rest. 
Figure 1. Study location within the municipality of West Nipissing, Ontario displayed on a WorldView-2 image acquired 2 July 2011.

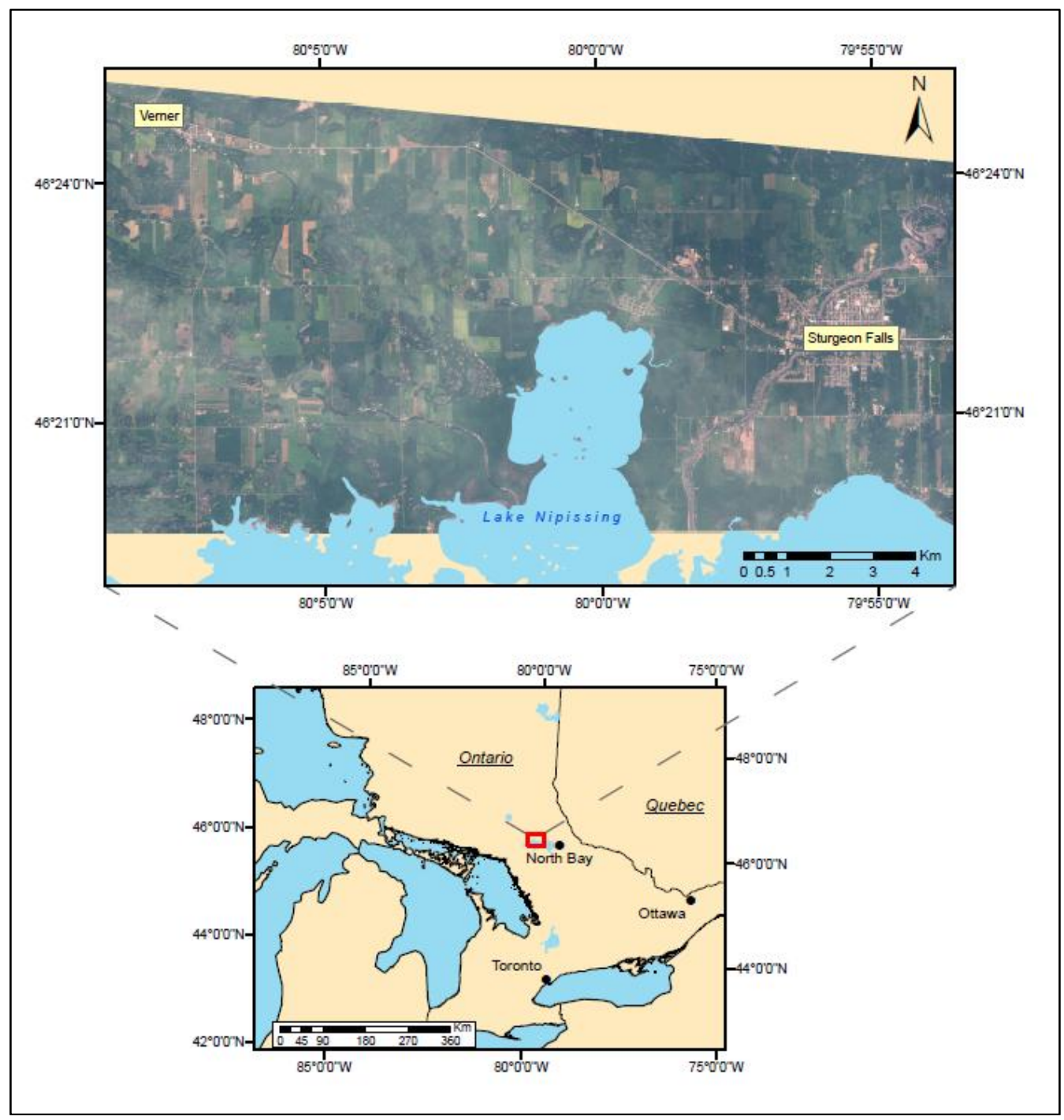

\section{Crop Types}

The five cash crops under investigation — barley, canola, oat, soybean and wheat - are common to the local farming community. Each crop has its own unique morphology upon reaching maturity, which theoretically results in unique scattering mechanisms. Canola (Brassica napus) (Figure 2) is an herbaceous species that undergoes several changes during its life cycle. After emerging, it produces several large leaves that spread out laterally across the soil. The plant then begins to quickly grow vertically with one or more stalks, which eventually produce yellow flowers. Once reaching a maximum height $(\sim 1.5 \mathrm{~m})$, the flowers begin to fall off as the plant produces long, skinny pods filled with seeds. The increase in biomass creates a thick canopy as the pods from neighbouring plants that often intertwine with one another. Soybean (Glycine max) (Figure 3) belongs to the legume family and creates a continuous thick canopy of large leaves often making row discernibility impossible at later 
stages. After maturity, the leaves fall off with only the main stem and flat bean pods remaining. Since barley (Hordeum vulgare) (Figure 4), oat (Avena sativa) (Figure 5) and wheat (Triticum spp.) (Figure 6), are all members of the grass family, their early development stages are very similar. However, once mature, the seed bearing structures are very different (Figures $4 c, 5 c$ and $6 c$ ).

Figure 2. Canola growth stages coinciding with weeks of RADARSAT-2 acquisitions. (a) 20 June (b) 11 July (c) 4 August (d) 28 August.

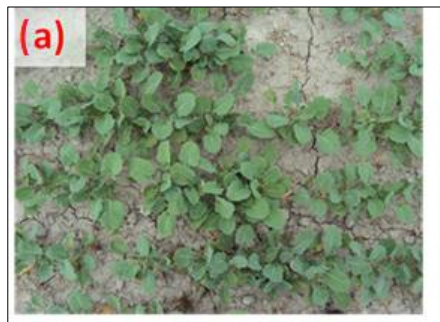

June $20^{\text {th }}$ (day 171$)$ $\mathrm{BBCH}$ stage 14

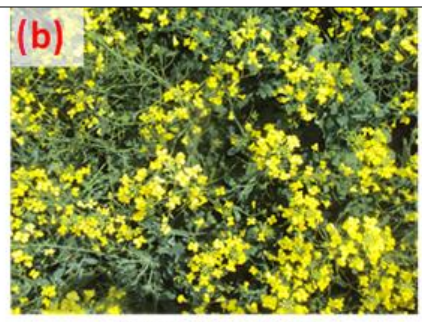

July $11^{\text {th }}$ (day 192 $\mathrm{BBCH}$ stage 65

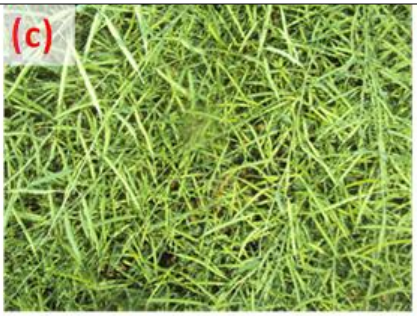

August $4^{\text {th }}$ (day 216) $\mathrm{BBCH}$ stage 76

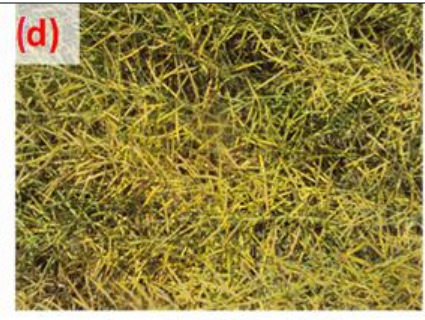

August $28^{\text {th }}$ (day 240) $\mathrm{BBCH}$ stage 86

Figure 3. Soybean growth stages coinciding with weeks of RADARSAT-2 acquisitions. (a) 20 June (b) 11 July (c) 4 August (d) 28 August.

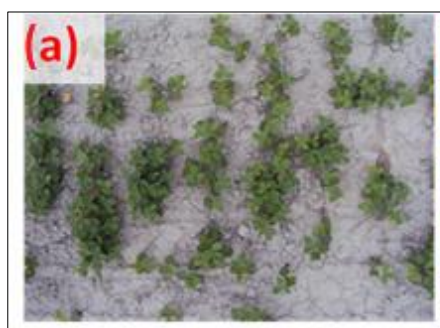

June $20^{\text {th }}$ (day 171) BBCH stage 12

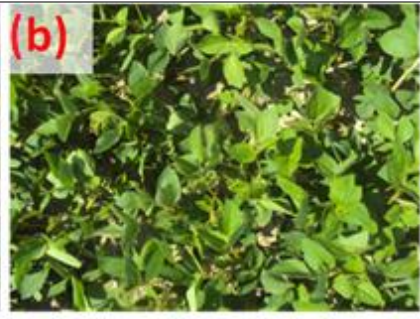

July $11^{\text {th }}$ (day 192) $\mathrm{BBCH}$ stage 60

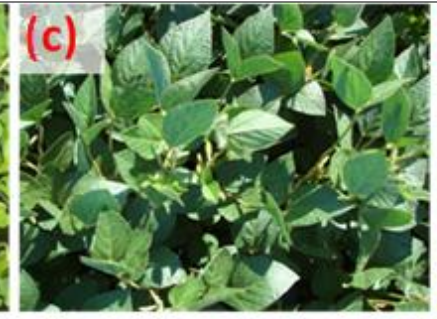

August $4^{\text {th }}$ (day 216) $\mathrm{BBCH}$ stage 73

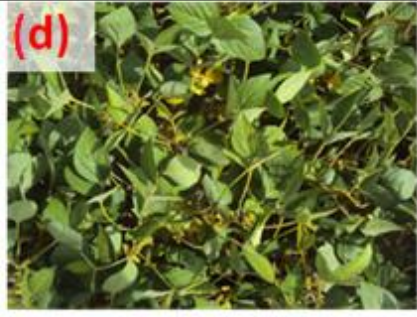

August $28^{\text {th }}$ (day 240) BBCH stage 87

Figure 4. Barley growth stages coinciding with weeks of RADARSAT-2 acquisitions. (a) 20 June (b) 11 July (c) 4 August.

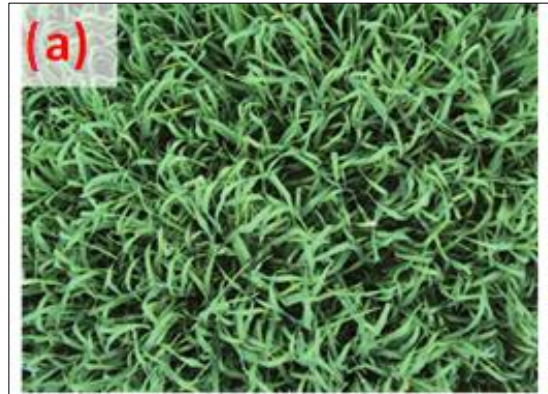

June $20^{\text {th }}$ (day 171$)$ $\mathrm{BBCH}$ stage 37

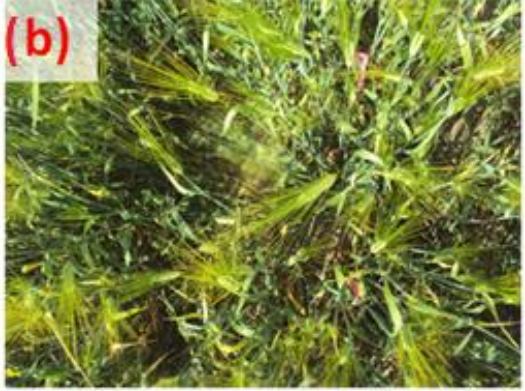

July $11^{\text {th }}$ (day 192) BBCH stage 69

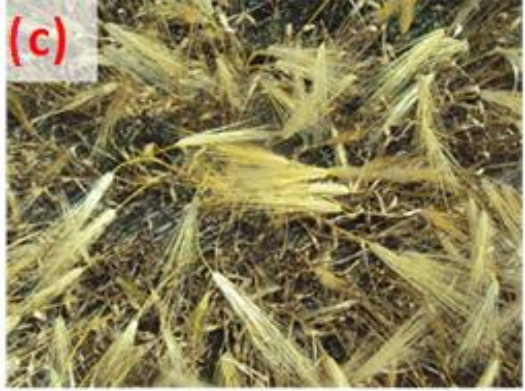

August $4^{\text {th }}$ (day 216) $\mathrm{BBCH}$ stage 87 
Figure 5. Oat growth stages coinciding with weeks of RADARSAT-2 acquisitions. (a) 20 June (b) 11 July (c) 4 August.

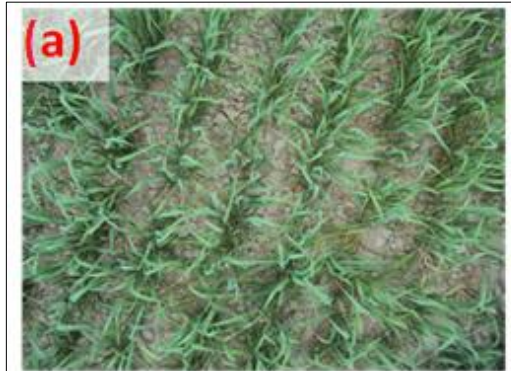

June $20^{\text {th }}$ (day 171)

$\mathrm{BBCH}$ stage 31

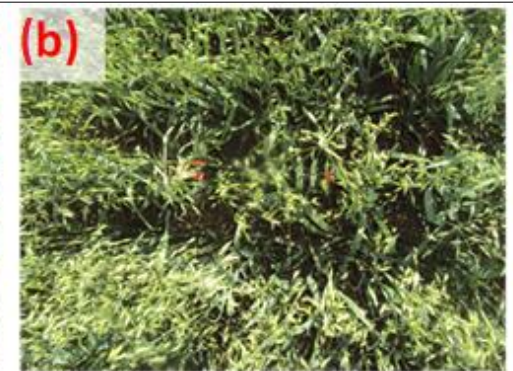

July $11^{\text {th }}$ (day 192)

BBCH stage 69

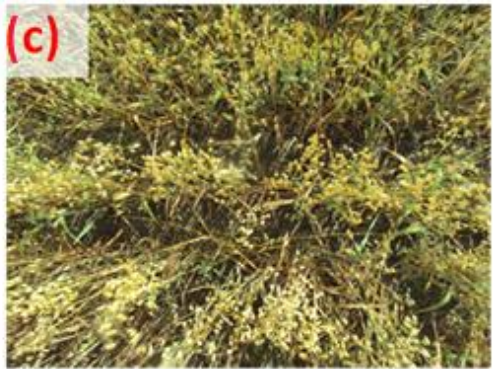

August $4^{\text {th }}$ (day 216) BBCH stage 87

Figure 6. Wheat growth stages coinciding with weeks of RADARSAT-2 acquisitions. (a) 20 June (b) 11 July (c) 4 August.

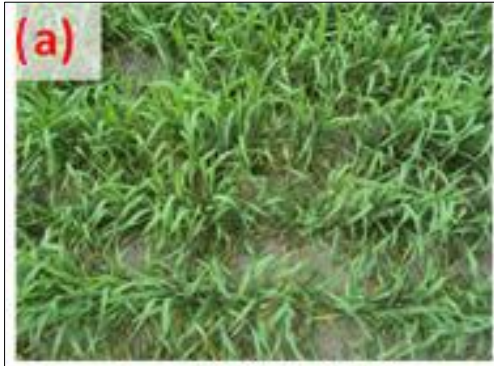

June $20^{\text {th }}$ (day 171)

$\mathrm{BBCH}$ stage 33

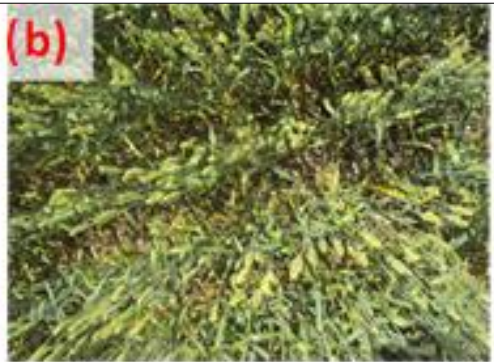

July $11^{\text {th }}$ (day 192)

BBCH stage 65

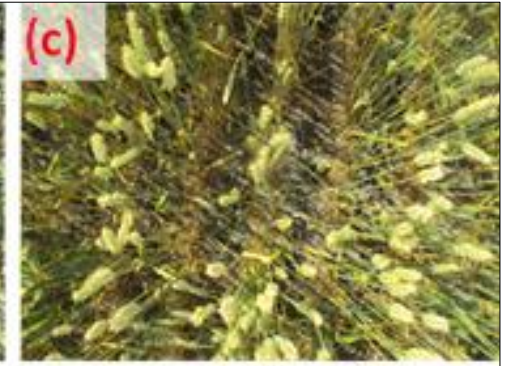

August $4^{\text {th }}$ (day 216) $\mathrm{BBCH}$ stage 85

\section{Methodology}

\subsection{Satellite Imagery}

Two sets of RADARSAT-2 Fine Quad-Pol beam mode images, based on incidence angle, were acquired over the 2011 growing season (June-September) (Table 1). These data were collected every three weeks at a steep $\left(26^{\circ}\right)$ and shallow $\left(41^{\circ}\right)$ incidence angle in order to determine if one angle was better at differentiating crop types and/or scattering mechanisms.

Table 1. 2011 RADARSAT-2 acquisitions.

\begin{tabular}{ccccc}
\hline Acquisition Date & $\begin{array}{c}\text { Day of } \\
\text { Year }\end{array}$ & $\begin{array}{c}\text { Polarization } \\
\text { (Beam Mode) }\end{array}$ & $\begin{array}{c}\text { Pixel Size } \\
(\mathbf{m})\end{array}$ & $\begin{array}{c}\text { Incidence Angle } \\
\left({ }^{\circ}\right)\end{array}$ \\
\hline 20 June 2011 & 171 & Polarimetric (FQ21) & 10 & 41 \\
11 July 2011 & 192 & Polarimetric (FQ7) & 10 & 26 \\
14 July 2011 & 195 & Polarimetric (FQ21) & 10 & 41 \\
4 August 2011 & 216 & Polarimetric (FQ7) & 10 & 26 \\
7 August 2011 & 219 & Polarimetric (FQ21) & 10 & 41 \\
28 August 2011 & 240 & Polarimetric (FQ7) & 10 & 26 \\
31 August 2011 & 243 & Polarimetric (FQ21) & 10 & 41 \\
21 September 2011 & 264 & Polarimetric (FQ7) & 10 & 26 \\
24 September 2011 & 267 & Polarimetric (FQ21) & 10 & 41 \\
\hline
\end{tabular}




\subsection{Field Data}

Five fields (Figure 7), one of each crop, were selected to study over the course of the summer. Please note that the anomaly in the upper right section of the canola field represents a vegetated rock outcrop and hence why it displays a different response and was not included in the sampling. The sampling design was modified from McNairn et al. [10] by selecting twenty-four (24) locations distributed throughout each field, organized into three transects (spaced $50 \mathrm{~m}$ apart) of eight points (spaced $10 \mathrm{~m}$ apart) (Figure 8). Phenology, using Biologische Bundesanstalt, Bundessortenamt and Chemische Industrie (BBCH) scales, and leaf area index (LAI), using an AccuPAR LP-80 ceptometer, were sampled on weekly visits to the field (Table 2). The LP-80 ceptometer is a portable device that simultaneously measures above- and below-photosythetically active radiation (PAR), used to approximate LAI [20]. Soil moisture was collected on days of acquisition using a Delta-T ThetaProbe soil moisture sensor.

Figure 7. RADARSAT-2 image, taken 4 August 2011, of agricultural study area (RGB: HH, HV, VV) ( $\mathrm{a}=$ barley, $\mathrm{b}=$ oat, $\mathrm{c}=$ wheat, $\mathrm{d}=$ canola, $\mathrm{e}=$ soybean).

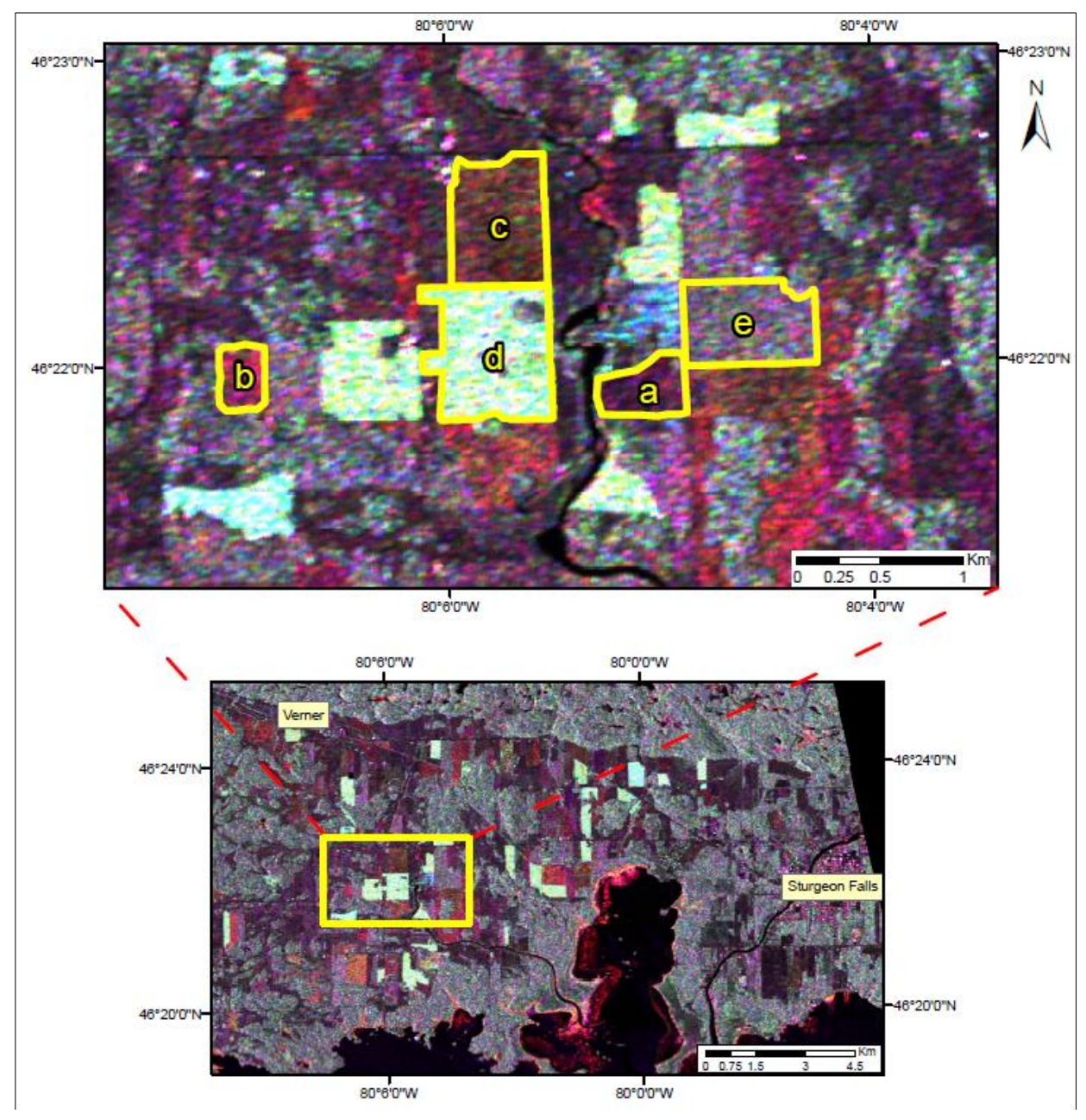


Figure 8. Sample locations for data collection within each field.

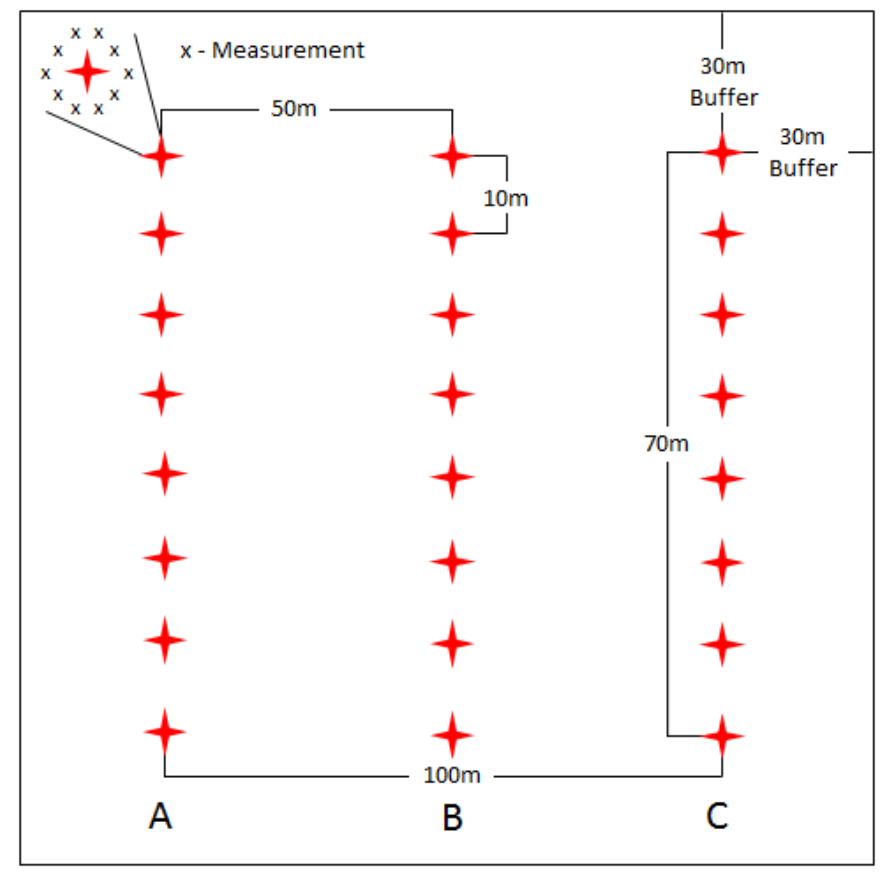

Table 2. Phenological, LAI and soil moisture field data for weeks corresponding with RADARSAT-2 acquisitions. Note that shaded cells represent no data due to harvest.

\begin{tabular}{|c|c|c|c|c|c|c|}
\hline \multirow[b]{2}{*}{ Crop } & \multirow[b]{2}{*}{ Parameter } & \multicolumn{5}{|c|}{ Week of Acquisition (Day of Year) } \\
\hline & & $\begin{array}{c}20 \text { June } \\
(171) \\
\end{array}$ & $\begin{array}{c}11 \text { July } \\
\text { (192) }\end{array}$ & $\begin{array}{c}4 \text { August } \\
(216)\end{array}$ & $\begin{array}{c}28 \text { August } \\
(240) *\end{array}$ & $\begin{array}{c}21 \text { September } \\
(264)\end{array}$ \\
\hline \multirow{4}{*}{ Soybean } & Avg. BBCH growth stage & 12 & 60 & 73 & 87 & \\
\hline & Avg. Height $(\mathrm{cm})$ & 10 & 56 & 92 & 90 & \\
\hline & Avg. LAI & N/A & 3.12 & 4.54 & 3.93 & \\
\hline & Avg. Soil Moisture (\%) & N/A & 18.5 & 12.4 & 11.3 & 21.8 \\
\hline \multirow{4}{*}{ Canola } & Avg. BBCH growth stage & 14 & 65 & 76 & 86 & \\
\hline & Avg. Height $(\mathrm{cm})$ & 19 & 137 & 151 & 145 & \\
\hline & Avg. LAI & N/A & 5.14 & 4.59 & 3.33 & \\
\hline & Avg. Soil Moisture (\%) & N/A & 16.7 & 14.0 & 13.5 & 21.9 \\
\hline \multirow{4}{*}{ Wheat } & Avg. BBCH growth stage & 33 & 65 & 85 & & \\
\hline & Avg. Height $(\mathrm{cm})$ & 49 & 89 & 90 & & \\
\hline & Avg. LAI & N/A & 3.03 & 2.16 & & \\
\hline & Avg. Soil Moisture (\%) & N/A & 14.4 & 10.8 & 11.6 & 18.7 \\
\hline \multirow{4}{*}{ Oat } & Avg. BBCH growth stage & 31 & 69 & 87 & & \\
\hline & Avg. Height $(\mathrm{cm})$ & 41 & 105 & 106 & & \\
\hline & Avg. LAI & N/A & 3.33 & 2.33 & & \\
\hline & Avg. Soil Moisture (\%) & N/A & 15.4 & 11.9 & 12.7 & 19.5 \\
\hline \multirow{4}{*}{ Barley } & Avg. $\mathrm{BBCH}$ growth stage & 37 & 69 & 87 & & \\
\hline & Avg. Height (cm) & 52 & 115 & 107 & & \\
\hline & Avg. LAI & N/A & 2.96 & 1.96 & & \\
\hline & Avg. Soil Moisture (\%) & N/A & 15.1 & 11.4 & 11.7 & 18.2 \\
\hline
\end{tabular}

* Rainfall on August 31 (DOY 243) prevented soil moisture collection, therefore value is expected to be higher than indicated for that week. 


\subsection{Data Processing}

Each image was ingested into the S4C scattering matrix using PCI Geomatica v.2012 (Figure 9). In this study, two sets of beam mode (FQ7 and FQ21) imagery were acquired. All images were ordered in the single look complex (SLC) format. During preprocessing, a 5 by 5 boxcar filter was used to reduce speckle [21,22]. The use of a boxcar filter is appropriate as it will remove speckle while preserving signal information. Additionally, the loss of spatial resolution associated with the boxcar filter is not of concern since the agricultural fields are homogeneous [23]. After the boxcar filtering, the SLC images were converted to multi-look SAR intensity images. The data were then converted to a symmetrized $3 \times 3$ covariance matrix which averages the cross-polarization backscatter intensities [21]. For mathematical details of these procedures, the reader is referred to Lee and Pottier [23] or Boerner et al. [24].

Figure 9. Flow diagram of processing and extraction methodology.

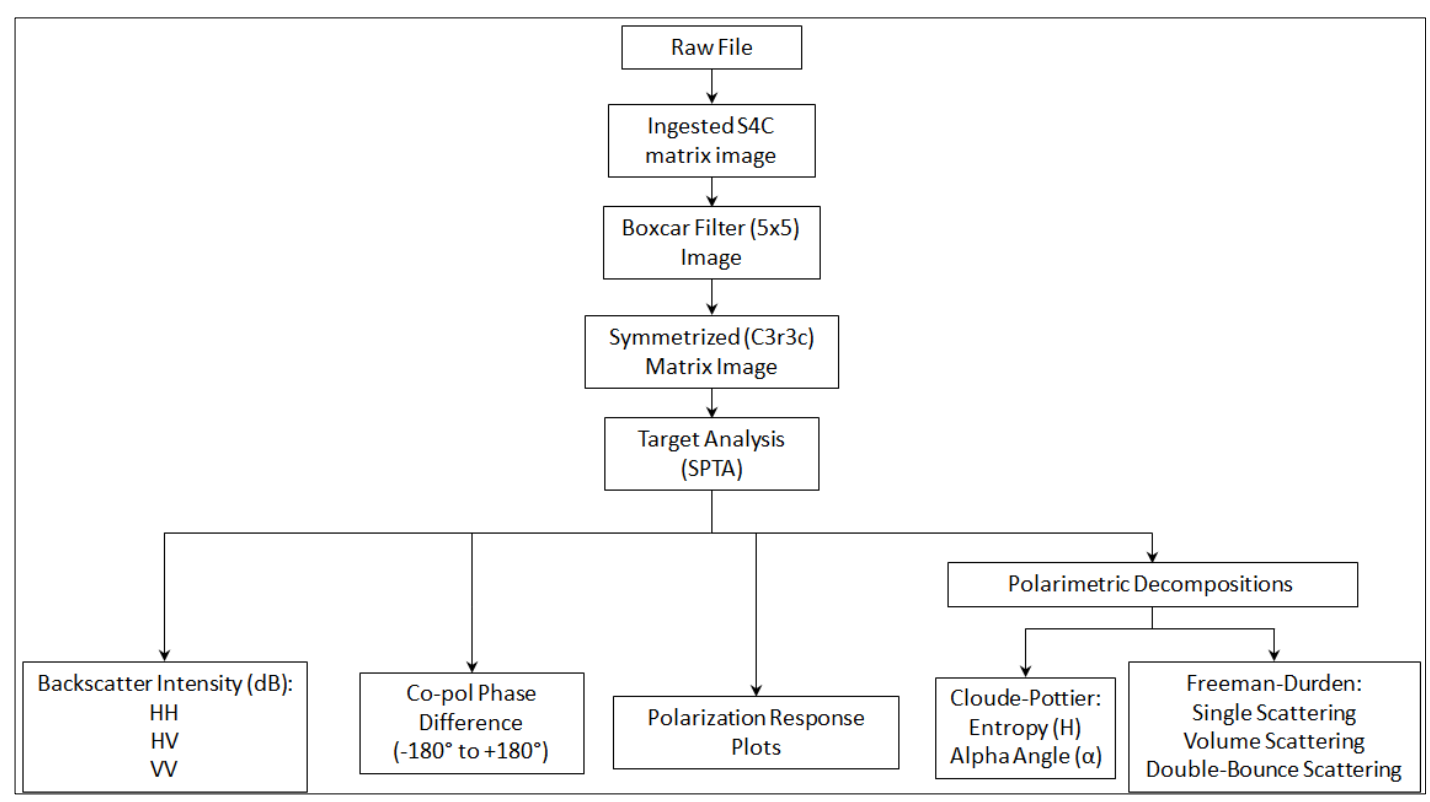

\subsection{Data Extraction}

Sample sites were selected from homogenous areas representative of the various crop types. The selection of the sites was based primarily on access (i.e., permission) to the target locations. Using optical satellite imagery from the same year, we identified identical remote targets and cross-validated their response visually, to justify the final target selection. For each type of target, a minimum sample of 1000 pixels was used to enable an adequate representation. However, given the extent and access of available sample sites, some target areas were smaller than others. Specifically, the area of each test site was 28.2 ha (canola), 27.5 ha (wheat), 25.6 (soybean), 13.8 (barley) and 10.1 ha (oat).

Using the SAR Polarimetry Target Analysis (SPTA) software extension in Geomatica 2012, backscatter intensity, co-polarized phase difference, pedestal height, polarimetric response plots and polarimetric decompositions were extracted from the four targets for each date of acquisition. For each type of target, a minimum sample of 1000 pixels was used to enable an accurate representation. The Cloude-Pottier decomposition plots were generated using the Canada Centre for Remote Sensing's 
Polarimetric Workstation (PWS) software [21]. For further detail of these procedures, the reader is referred to [25-28].

\section{Results and Discussion}

\subsection{Backscatter Intensity}

Based on the extracted data, an inverse relationship was observed between backscatter intensity and incidence angle, as an increase in incidence angle will generate lower backscatter values. This is likely due to the steep incidence angle (FQ7) being closer to nadir (i.e., more perpendicular to Earth) and thus reducing the chance for the signal to deflect away from the satellite (i.e., specular reflection). Figure 10 shows this trend as the shallow incidence angle (FQ21) intensity is generally lower than the steep incidence angle for all crop types. One exception to the pattern is between 28 August (DOY 240), the steep incidence angle, which has lower backscatter values than the acquisition on 31 August (DOY 243), the shallow incidence angle. Upon examining precipitation data, it was found that very little precipitation occurred before the 28th, leading to dry soil conditions. Within the next few days, several millimeters of rain fell and increased the soil moisture, possibly leading to the higher observed response on the 31st [9].

The HH backscatter intensities (Figure 10) for many of the crops display a slight increase from 20 June (DOY 171) to 14 July (DOY 195) as the main stem development occurs. This trend is similar to what was observed by McNairn et al. [3], who suggested that an increase in biomass will lead to an increase in $\mathrm{HH}$ backscatter. Conversely, a decrease in biomass will result in a decrease in backscatter. For example, once the cereals begin to ripen, the plants dry out and lose their leaves, thus decreasing their biomass. This is evident when barley senesces (BBCH stage 83-89) as its LAI drops from 2.96 to 1.96, while at the same time, backscatter for both incidence angles also decreases. There appears to be some separation between the cereals and soybean and canola in FQ21 acquisitions between 20 June (DOY 171) and 7 August (DOY 219). This may be due to the observed in-field variability with regards to crop height for canola and soybean which, unlike cereal crops, shows a less uniform and level canopy. Another potential reason for the difference may be based on the growth stage the crops have achieved. The cereals are beginning to ripen earlier (BBCH stage 83-89), which involves the plant drying out (i.e., lower dielectric property) and losing leaves, thus decreasing the amount of biomass and resulting in lower backscatter. In contrast, the soybean and canola are still developing pods (BBCH stage 70-79) and becoming denser, therefore the backscatter is higher. The HV backscatter intensities (Figure 10) show a greater separation of canola and soybean from the cereal crops at both incidence angles. As the soybean and canola reach later growth stages $(\mathrm{BBCH}$ stage 73-76), their LAI values peak at around 4.5-5, indicating very high biomass. When this occurs, the canopies become more complex and are oriented in such a way that they depolarize a greater amount of the incident wave than the cereals. It should be noted that for the 31 August (DOY 243) acquisition, cereal HV response increases. However, this increase in backscatter can again be attributed to the increase in soil moisture following a precipitation event. The VV backscatter intensities (Figure 10) are very similar to that of the $\mathrm{HH}$, as an increase in biomass results in higher backscatter. Once again, there is separation between the cereals and soybean and canola in July and August, due to varying crop height, growth stages and biomass or canopy density. 
Figure 10. HH (Top), HV (Middle), and VV (Bottom) backscatter intensities for $26^{\circ}$ (Left) and $41^{\circ}$ (Right) incidence angles of all crop types based on RADARSAT-2 fine quad beam modes. Note that dashed lines indicate harvest of cereals (Red), and soybean and canola (Black).
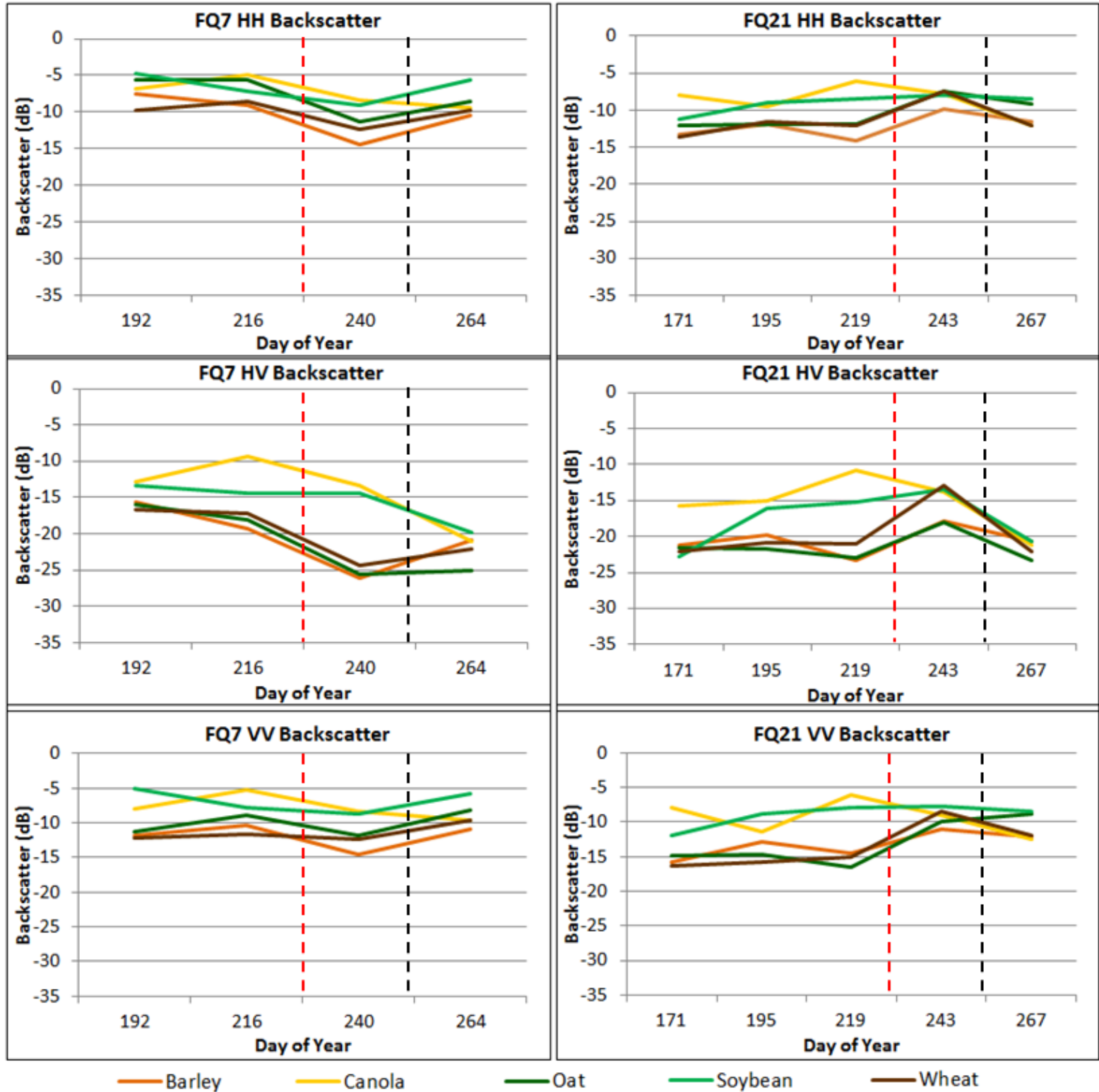

Figures 11 and 12 are RGB composite images created from multi-channel SAR intensity (power) images. A linear enhancement was applied to the RGB composite images. Figure 11 displays a composite (RGB: HH, HV, VV) of backscatter intensities based on a polarimetric RADARSAT-2 $41^{\circ}$ fine beam mode (FQ21) image taken 14 July (DOY 195) which can be used to distinguish which polarizations are dominant for each crop, giving an indication as to which scattering mechanisms are contributing for each target. For example, since canola has developed a dense canopy by the time of acquisition, HV scattering is the highest of any crop, resulting in the light green observed. Cereals on the other hand, have very low HV contribution compared to canola, and higher HH than VV, and therefore appear dark red. Soybean has equal $\mathrm{HH}$ and VV scattering therefore the red and blue 
combine to appear purple. Although it has a high HV component, it is less than canola; therefore the green contribution is not as strong.

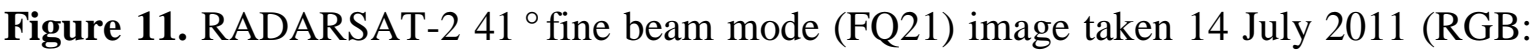
$\mathrm{HH}, \mathrm{HV}, \mathrm{VV}$ ) of study area in West Nipissing, Ontario. The dynamic range of each polarization is $34.3 \mathrm{~dB}$ for $\mathrm{HH}, 40 \mathrm{~dB}$ for $\mathrm{HV}$ and $31.8 \mathrm{~dB}$ for $\mathrm{VV}$.

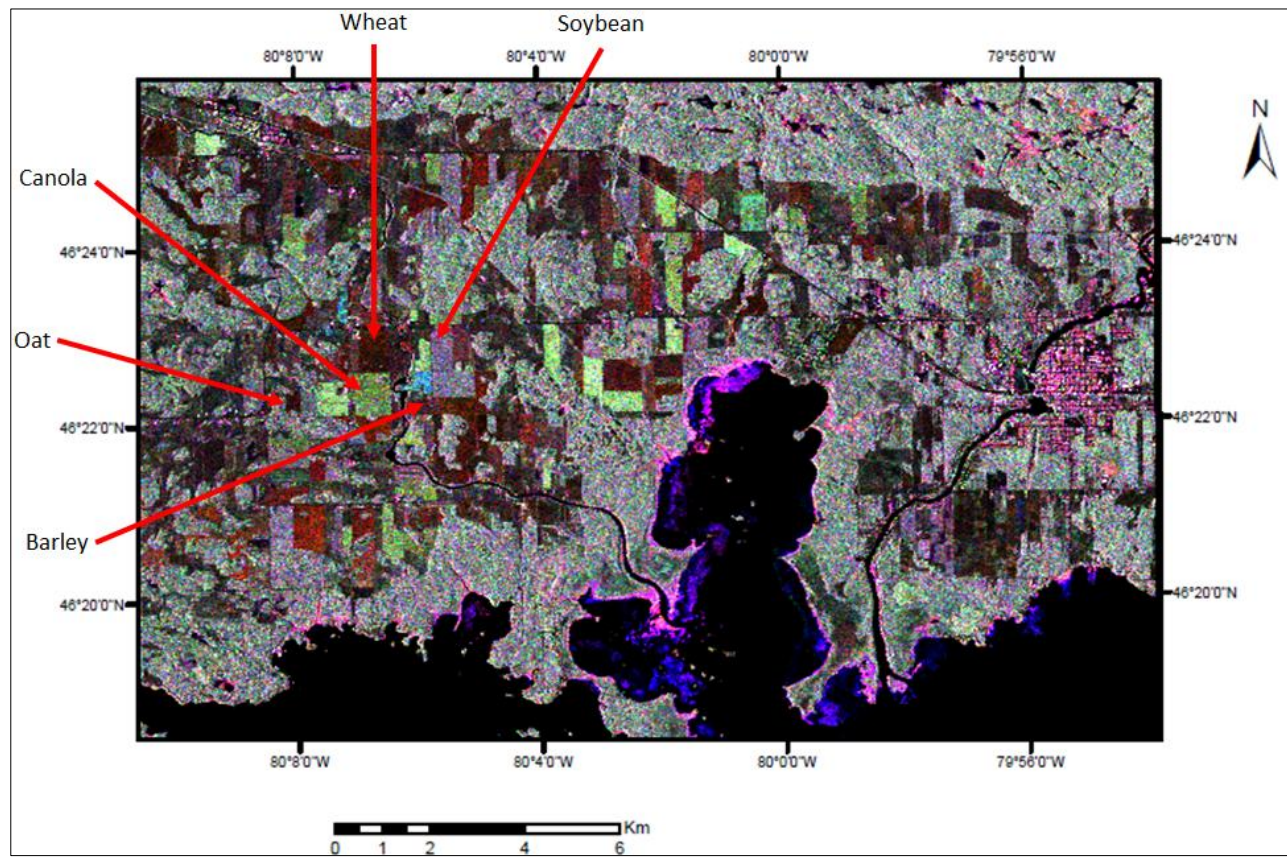

Figure 12. Temporal variation in HV backscatter (RGB: 20 June, 7 August, 24 September) based on RADARSAT-2 $41^{\circ}$ fine beam mode (FQ21) images in 2011. The dynamic range for each date is $39.8 \mathrm{~dB}$ for 20 June, $38.5 \mathrm{~dB}$ for 7 August and $27.3 \mathrm{~dB}$ for 24 September.

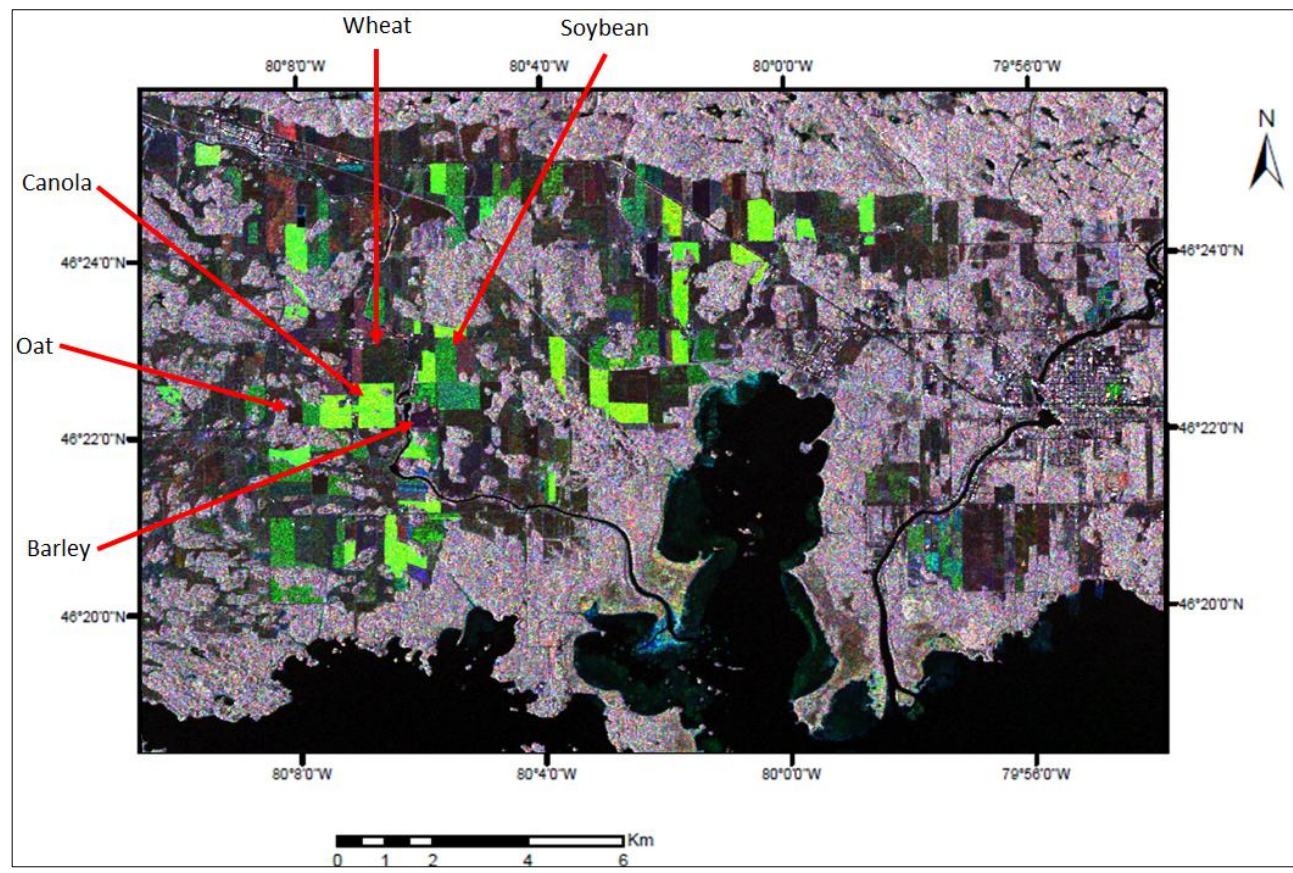


Figure 12 is a composite based on the HV backscatter intensity from three polarimetric RADARSAT- $241^{\circ}$ fine beam mode (FQ21) images taken over the course of the growing season. The three dates shown are 20 June (DOY 171) in the red band, 7 August (DOY 219) in the green band, and 24 September (DOY 267) in the blue band. From the image, it is apparent that canola had the highest cross-polarized return on 7 August, with the bright green colour. This would make sense given the canopy reached a peak in density, while there was very little crop on 20 June and no crop on 24 September since it had already been harvested. Therefore there is no contribution from the red or blue bands. This is also similar for soybean, but the HV response on 7 August was not as strong as canola, and therefore the intensity of green is darker. The cereal crops had very little influence on cross-polarization for all three dates, relative to canola and soybean; therefore appear black in the image. The cereal crops grow long thin leaves and maintain defined rows throughout the growing season, whereas canola and soybean grow large broad leaves and spread out laterally. The wider, denser canopies of the canola and soybean provide ideal orientations for depolarizing the signal when compared to the cereal crops.

\subsection{Co-Polarized Phase Difference}

As previously mentioned, cereal crops like barley, oat and wheat are thin and maintain discernible rows throughout their growth stages. These properties allow for double-bounce and volume scattering to occur simultaneously within the cereal crops. Figure 13 shows the co-polarized (HH-VV) phase difference for both incidence angles, and the cereal crops clearly indicate some delay in the co-pol responses. It is possible that one of the polarizations penetrates between the rows allowing various types of double-bounce interactions (e.g., soil-vegetation) to occur, whereas the other polarization cannot penetrate as deep and is reflected back sooner. Canola and soybean form dense canopies, creating a rough surface which limits double-bounce. Slight variations in phase difference for these crops are due to volume scattering. Skriver et al. [2] observed similar results between barley, wheat and canola, among other crops types.

Figure 13. Co-polarized (HH-VV) phase difference for RADARSAT-2 $26^{\circ}$ (Left) and $41^{\circ}$ (Right) incidence angles of all crop types. Note that dashed lines indicate harvest of cereals (Red), and soybean and canola (Black).

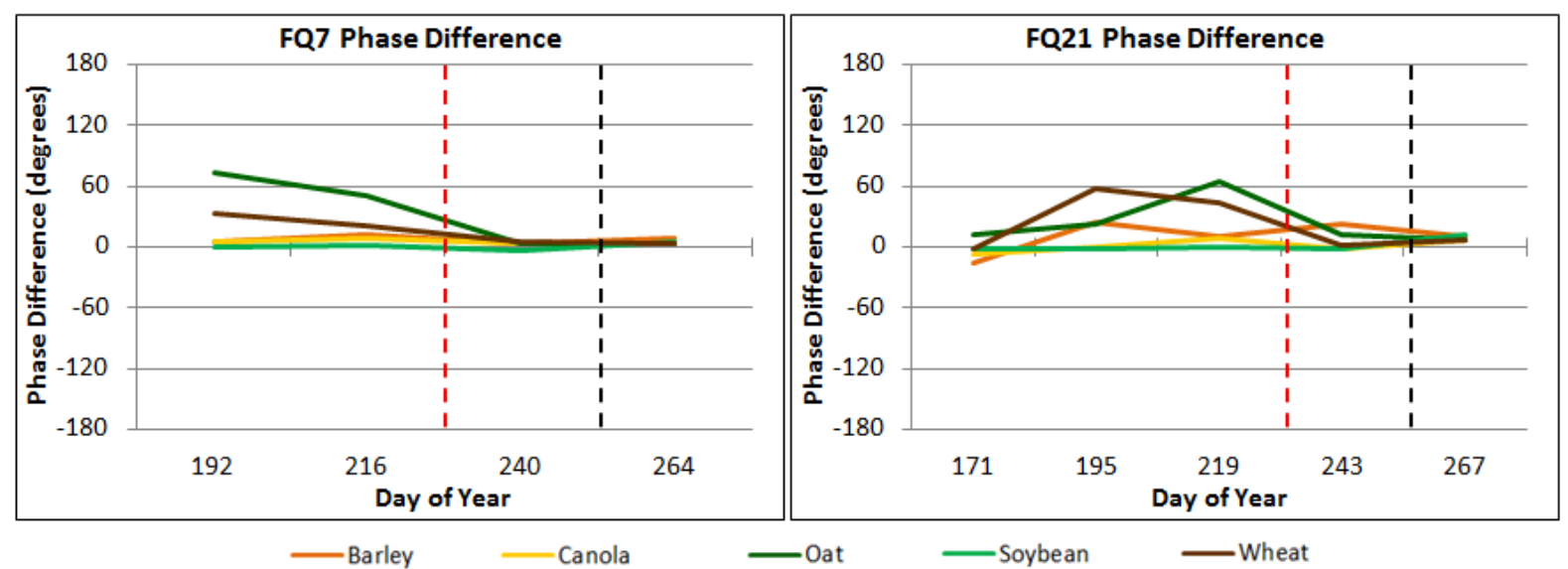




\subsection{Polarimetric Response Plots and Decompositions}

Each crop will now be discussed individually for polarimetric response plots and decomposition results. Given the amount of data derived, only a few examples of response plots and Cloude-Pottier decomposition graphs have been included. For all polarimetric response plot and decomposition results, please refer to the supplementary online material. To facilitate comparisons between crops, the intensity of the polarimetric responses has been normalized between 0 and 1 [10]. To date, very few studies have considered the temporal variations of the polarimetric responses of crops, and therefore only certain growth stages can be verified by previous work. For this study, since satellite acquisitions began mid-way through the growing season, there are no results for early crop stages. However, at such earlier stages, it is more likely that the soil component would dominate SAR response. Although van Zyl et al. [25] showed that polarimetric response plots are dependent on incidence angle, very little change was evident between the responses of the FQ7 and FQ21 beam modes. Please note that when conditions of entropy are quite low, the interpretation of the average alpha angle is more challenging [26]. However, given that the majority of low entropy values observed in this study corresponded with harvested fields, we employed the average alpha angle, as opposed to identifying the dominant alpha angle.

\subsubsection{Barley}

Early acquisition co-polarized plots show dominance in the $\mathrm{HH}$ response over the VV response, coinciding with the backscatter intensities shown in Figure 10. The 11 July (DOY 192) signatures (Figure 14a-b) are similar to those found by Skriver et al. [2] for approximately the same growth stage (i.e., BBCH stage 69). An increase in pedestal height from 20 June (DOY 171) to 14 July (DOY 195) indicates an increase in volume scattering, due to a rise in biomass (LAI = 2.96). For the same period, the cross-polarized responses also suggest the case of a strong influence from volume scattering. As the barley reaches maturity and begins to senesce $(\mathrm{BBCH}$ stage 87 ; LAI $=1.96)$ both the dielectric properties and the biomass decrease, thus reducing the cross-polarization response and pedestal height with increasing influence from surface scattering (Figure 14c,d). At the same time, the heads of the barley become heavy and lean over (Figure 4c) which may contribute to the observed increase in the VV response. Once the crop is harvested, the responses (Figure 14e,f) match the post-harvest, residue covered cereal field described by McNairn et al. [10].

The Cloude-Pottier decomposition for 11 July (Figure 15a) categorizes the majority of the barley pixels in zone 4 (volume), coinciding with the strong cross-polarized response and pedestal height. As biomass decreases, we see in the 7 August (DOY 219) decomposition (Figure 15b), the cluster has shifted between zones 4 and 5 (rough surface), further supporting the response plot interpretation that surface scattering is becoming dominant. After the barley has been harvested, the entropy (i.e., disorder of the target) lowers considerably. Therefore the decomposition (Figure 15c) shifts further into zone 5 as well as zone 8 (smooth surface). The Freeman-Durden decomposition results (Figure 16) resemble the Cloude-Pottier decompositions and the response plots. 11 July was classified mainly as volume scattering, while double-bounce also contributed. As previously mentioned, 7 August was greatly influenced by surface scattering, which appears in the Freeman-Durden 
decomposition. Finally, on 21 September (DOY 264), surface scattering becomes the main contributor as there is no standing barley remaining.

The 31 August image (DOY 243) generated an unexpected result as the Cloude-Pottier decomposition is split between zones 4 (volume) and 5 (surface), and the Freeman-Durden decomposition showed an increase in volume scattering, even though the crop had been harvested. Even though soil roughness can result in higher entropy, comparisons to other bare soil decompositions (31 August and 24 September) suggest that this occurrence was the result of increased soil moisture from a rainfall event. A similar observation of increased entropy and alpha angle due to increased soil moisture was also found by Baghdadi et al. [29].

Figure 14. Barley co- (Left) and cross-polarization (Right) polarimetric response plots based on RADARSAT-2 fine-quad beam modes for (a,b) 11 July, (c,d) 7 August, and (e,f) 21 September.

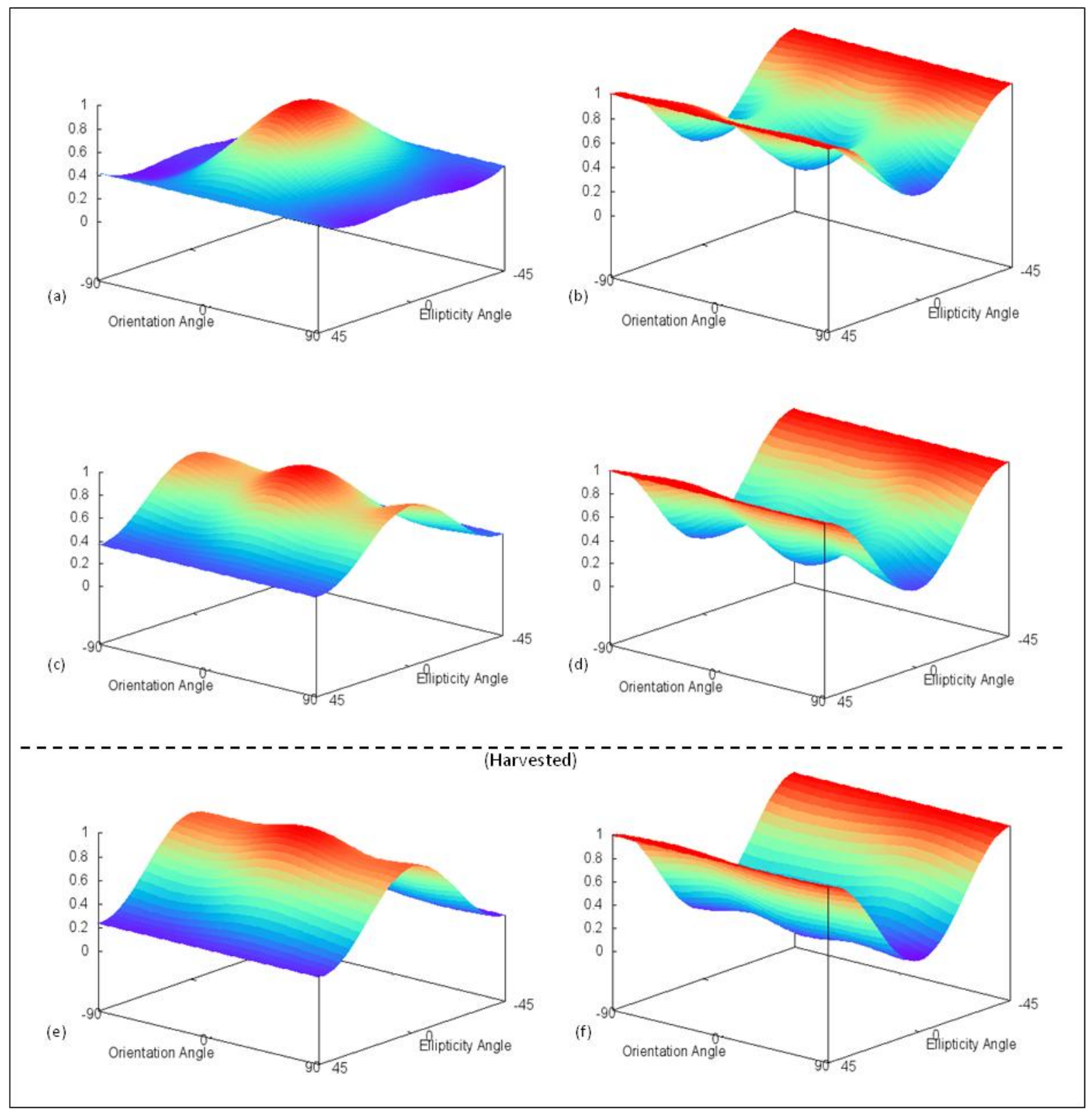


Figure 15. Barley Cloude-Pottier H/ $\alpha$ decomposition based on RADARSAT-2 fine-quad beam modes for (a) 11 July; (b) 7 August; and (c) 21 September.
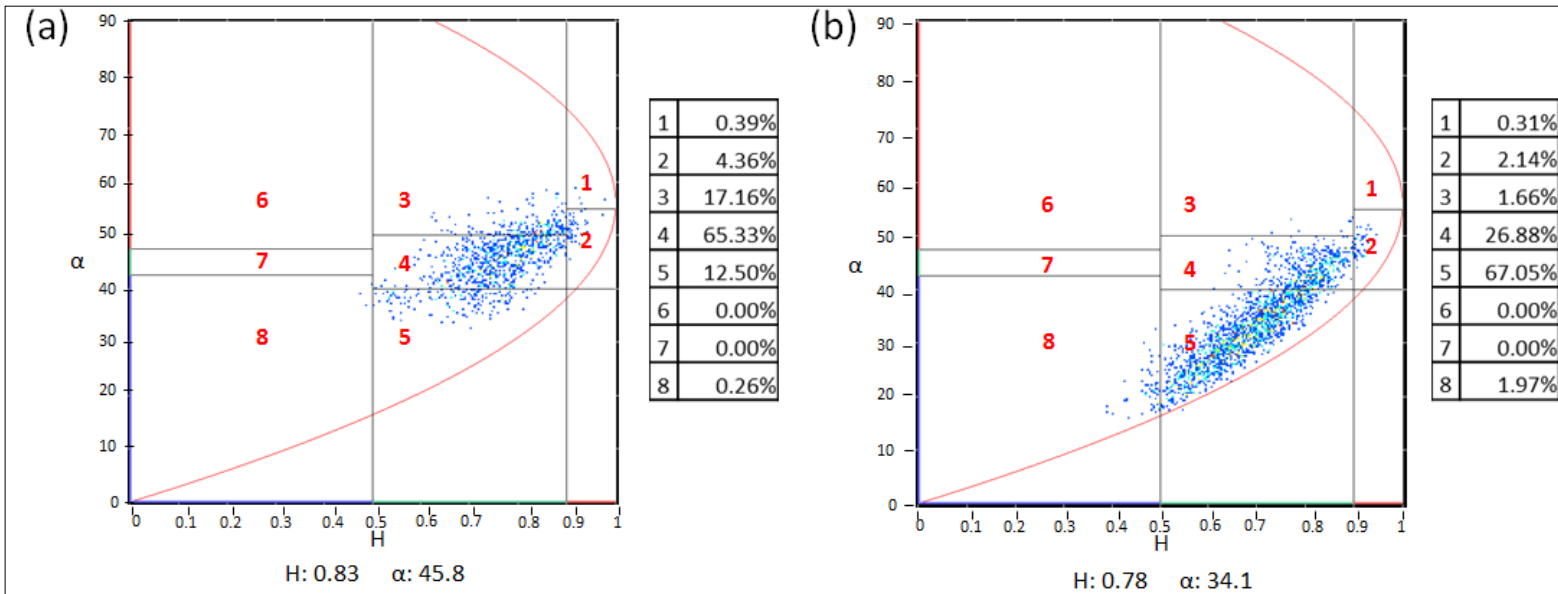

(c)
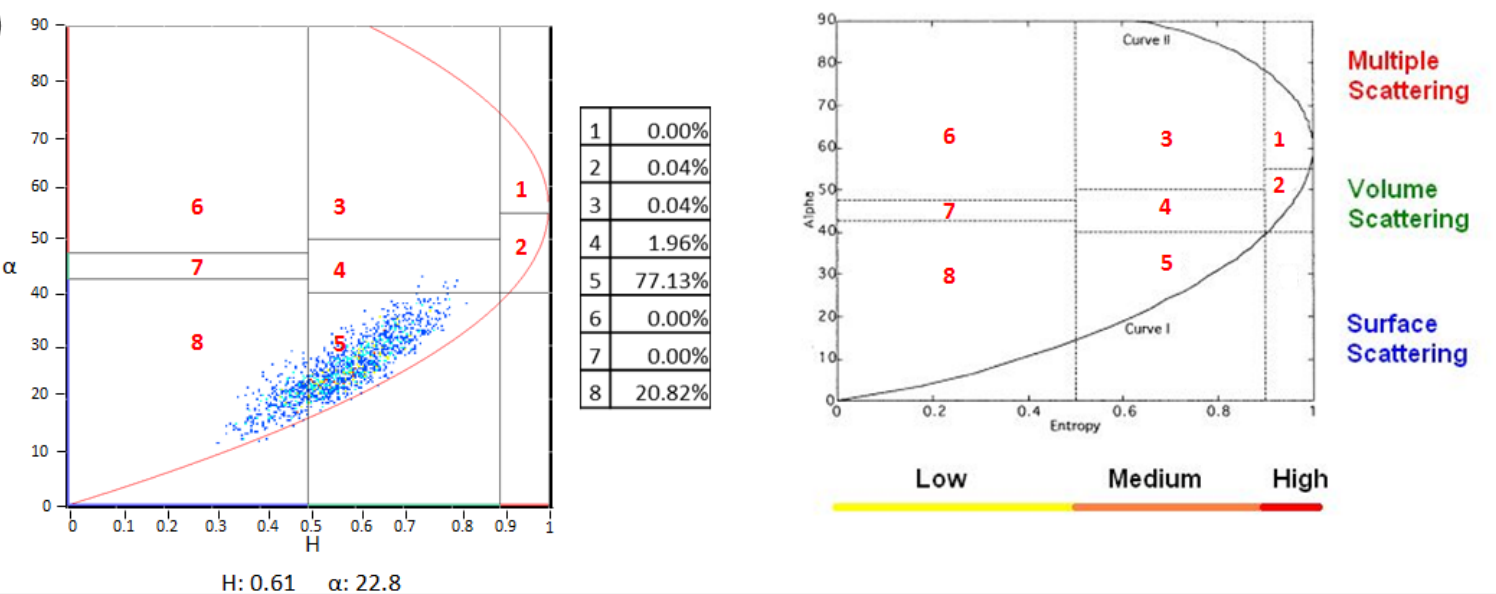

Figure 16. Barley Freeman-Durden decomposition for (a) $41^{\circ}$ and (b) $26^{\circ}$ incidence angles based on RADARSAT-2 fine-quad beam modes. Note that circled days coincide with polarization response plot and Cloude-Pottier decomposition dates; dashed line indicates harvest.

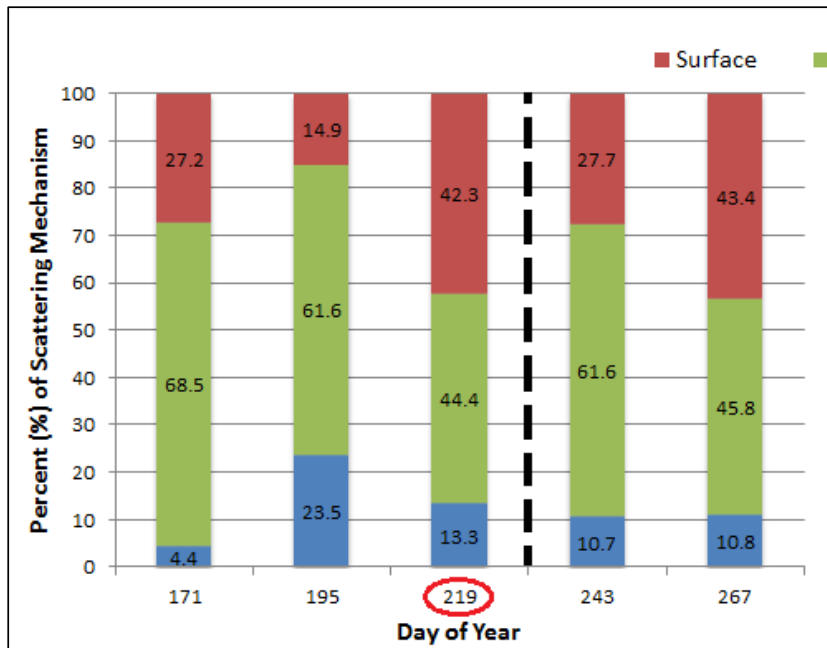

(a)

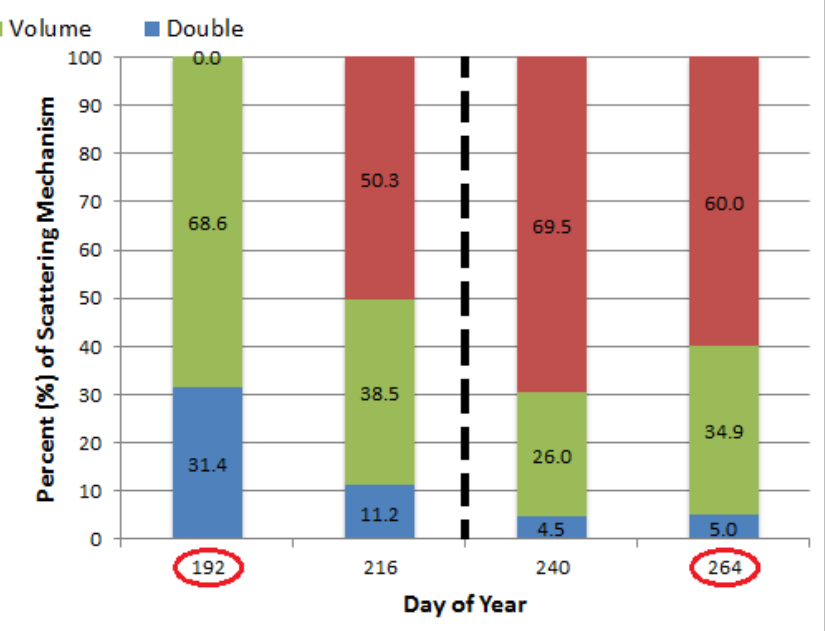

(b) 


\subsubsection{Canola}

On 20 June (DOY 171), canola had reached BBCH stage 14 and emerged approximately $20 \mathrm{~cm}$ (Figure 2a) above the surface and thus the polarization response plots resembled that of a rough surface (Figure 17a,b). Over time, the response began to exhibit signs of volume scattering with a higher pedestal height and increased cross-polarization backscatter, as was observed on 4 August (DOY 216) (Figure 17c,d). This was expected as a result of canola's dense canopy in later stages of growth (i.e., $\mathrm{BBCH}$ stage 65 ; $\mathrm{LAI}=4.59$ ), and was comparable to the canola response described by Skriver et al. [2]. It should be noted that for a target of random particles, the response plots will not display a dominant scattering orientation, hence, the smoothness of the response plots for canola. After harvest, the field returned to that of a rough surface and is similar to the results of a harvested canola field as reported by McNairn et al. [10] (Figure 17e,f).

Figure 17. Canola co- (Left) and cross-polarization (Right) polarimetric response plots based on RADARSAT-2 fine-quad beam modes for (a,b) 20 June, (c,d) 4 August, and (e,f) 21 September.

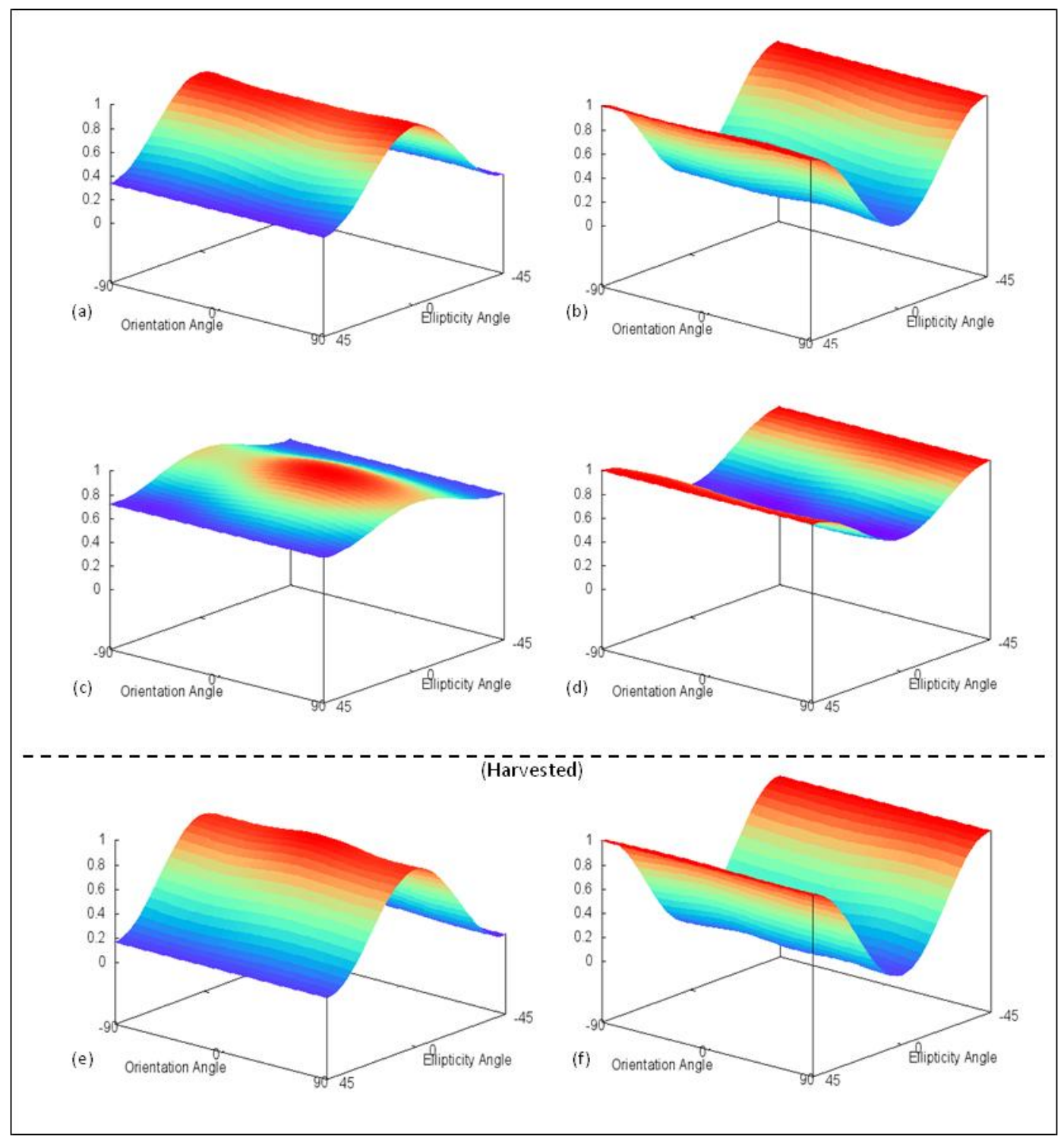


The transition from rough surface to volume scattering was also evidenced in the Cloude-Pottier decompositions. Figure 18a shows the 20 June decomposition in zone 5 (rough surface), which is then followed by the shift into zones 2 (dense volume) and 4 (volume) on 4 August (Figure 18b). Similar to the bare barley field, the canola decomposition returns to surface scattering zones 5 and 8 on 21 September (DOY 264) (Figure 18c). Meanwhile, the 20 June Freeman-Durden decomposition (Figure 19) attributes the scattering between a rough surface and volume scattering. These results coincide with the response plots and Cloude-Pottier decomposition. Soon after 20 June, there is a considerable increase in volume scattering attributing as much as $100 \%$ on 4 August. The post-harvest Freeman-Durden decomposition resembles the early stage (i.e., DOY 171) result with a strong surface scattering component.

Unlike the cereals, canola did not exhibit the backscatter effects of increased soil moisture on 31 August (DOY 243) possibly due to the crop not yet being harvested, but still had a dense enough canopy to prevent the signal from reaching the soil surface. Consequently, no enhanced backscatter was observed for the 31 August (DOY 243) image.

Figure 18. Canola Cloude-Pottier H/ $\alpha$ decomposition based on RADARSAT-2 fine-quad beam modes for (a) 20 June; (b) 4 August; and (c) 21 September.

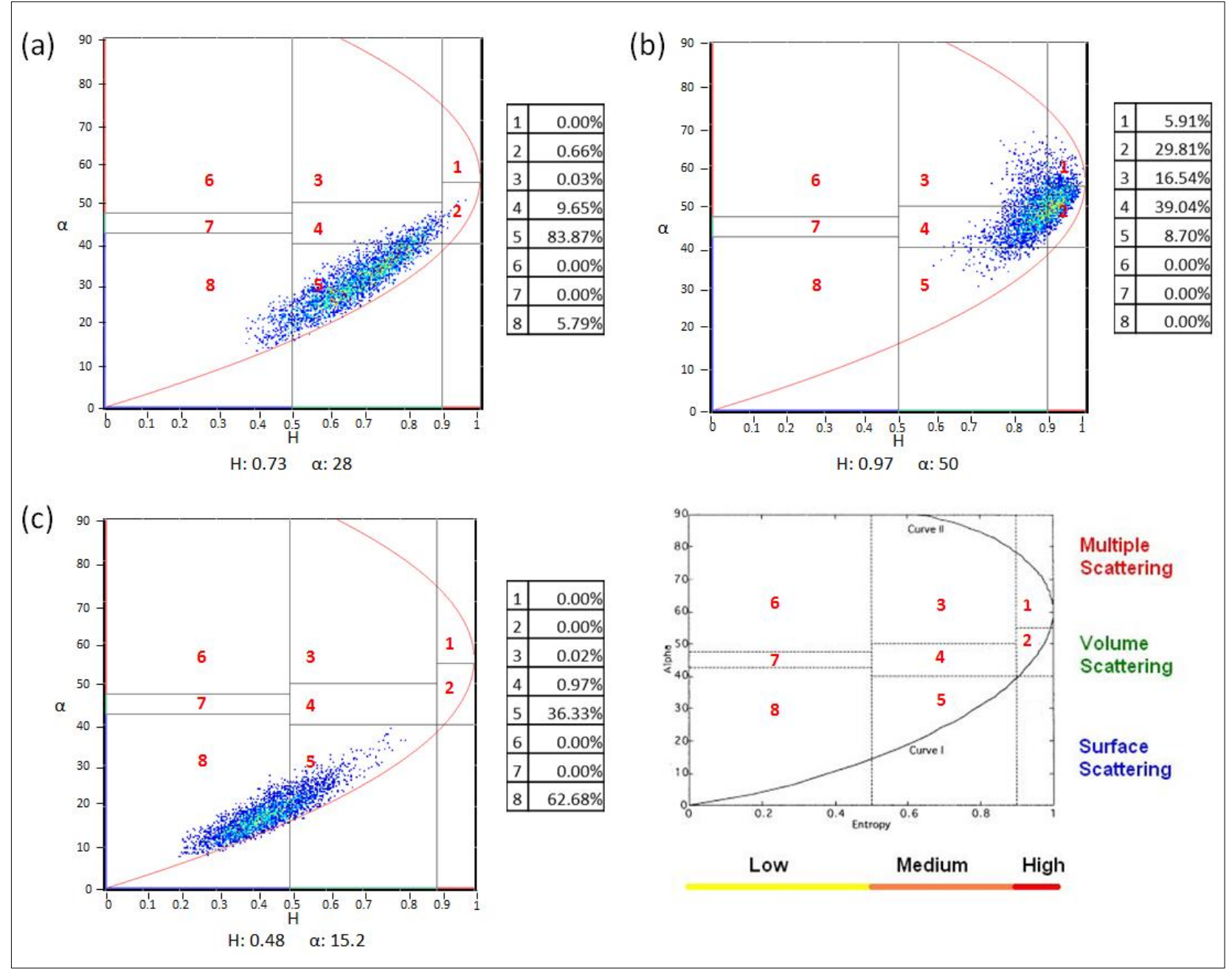


Figure 19. Canola Freeman-Durden decomposition for (a) $41^{\circ}$ and (b) $26^{\circ}$ incidence angles based on RADARSAT-2 fine-quad beam modes. Note that circled days coincide with polarization response plot and Cloude-Pottier decomposition dates; dashed line indicates harvest.

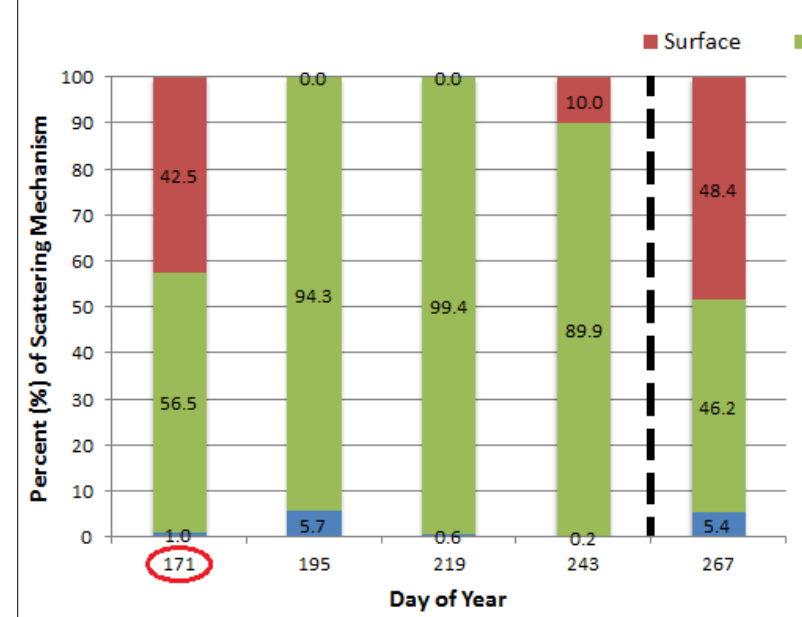

(a)

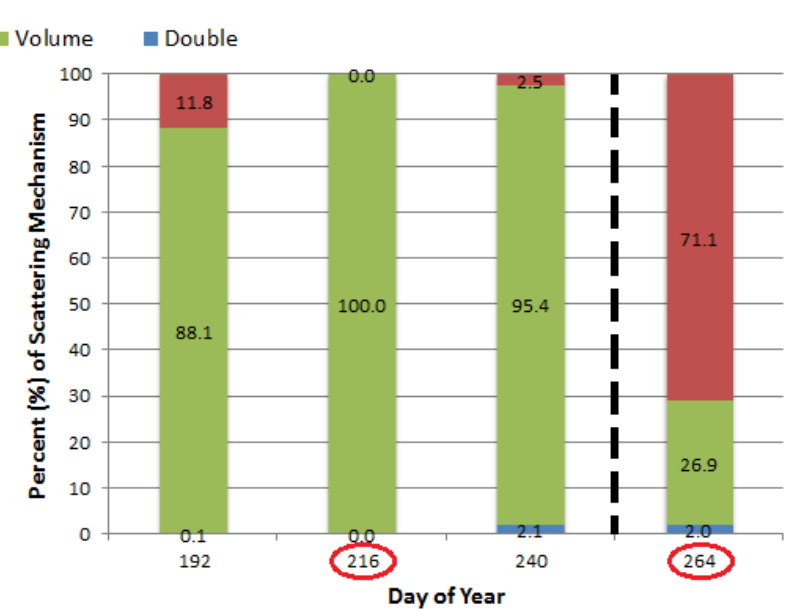

(b)

\subsubsection{Oat}

Similar to barley, oat had begun reaching mid growth stages (i.e., BBCH stage 31) by late June and consequently, displayed a maximum response for the $\mathrm{HH}$ polarization at that time (Figure 20a). The presence of cross-polarized response and a moderate pedestal height indicates some depolarization of the signal was taking place (Figure 20b). The pedestal height gradually increased thereafter, as the crop canopy became denser in mid-July (BBCH stage 69; LAI = 3.33) (Figure 5b). The 7 August (DOY 219) responses (Figure 20c,d) are similar to cereal responses observed by Skriver et al. [2] during late growth stages $(\mathrm{BBCH}$ stage 87$)$ as a result of both the dielectric properties and biomass decreasing $(\mathrm{LAI}=2.33$ ). However, the oat did not exhibit an increase in VV scattering like the barley, possibly due to the still erect nature of the oat heads (Figure 5c). Eventually, the crop returned to that of a rough surface as observed by McNairn et al. [10] for post-harvest fields of cereal crops (Figure 20e,f).

The Cloude-Pottier decomposition for 20 June (Figure 21a) categorizes the majority of the oat pixels in zones 4 (volume) and 5 (surface), coinciding with the cross-polarized response and pedestal height. Since biomass increased by 7 August (DOY 219), the decomposition (Figure 21b) has shifted to occupy mainly zone 4, further supporting the notion that volume scattering is becoming dominant. After the oat has been harvested, the decomposition (Figure 21c) shifts to zone 8 surface scattering. The Freeman-Durden decomposition results (Figure 22) resemble the Cloude-Pottier decompositions as well as the response plots. 20 June was classified between surface and volume scattering. It is interesting to note that for 7 August (DOY 219), the Freeman-Durden decomposition displays a strong double-bounce contribution, which parallels the peak in phase difference in Figure 13b. As expected, the Freeman-Durden decomposition of the harvested field (DOY 267) attributes a large component of the signal to surface scattering. 
Once again, it is important to note the effect of increased soil moisture on the 31 August decompositions, as they indicate higher than anticipated entropy and volume scattering when the crop had already been harvested.

Figure 20. Oat co- (Left) and cross-polarization (Right) polarimetric response plots based on RADARSAT-2 fine-quad beam modes for (a,b) 20 June, (c,d) 7 August, and (e,f) 24 September.

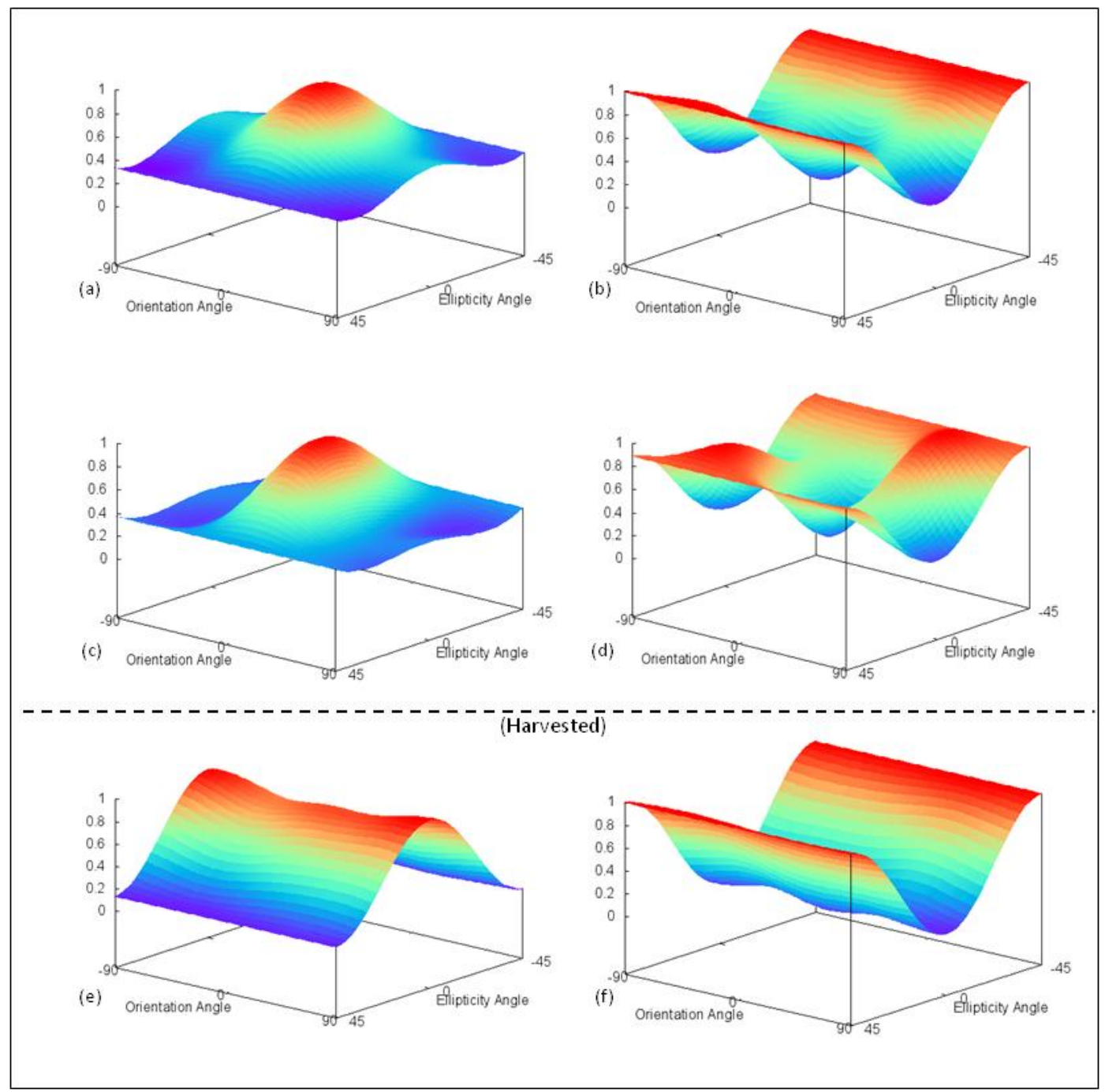

\subsubsection{Soybean}

Surface scattering dominates early stages of soybean, given that the crop was only at growth stage 12 and $10 \mathrm{~cm}$ tall (Figure 3a). By 14 July (DOY 195) the crop has developed broad leaves (Figure 3b) and the LAI had increased to 3.12 resulting in an increase in the co- and cross-polarized intensities (Figure 23a,b), and a higher pedestal height which indicate the presence of volume scattering. In early August (Figure 3c), the canopy became quite dense and thus the polarization response plots continued to increase. This coincides with recorded LAI reaching their highest value. On 28 August (DOY 240), soybean was reaching maturity (BBCH stage 87 ) and the presence of leaves and pods (Figure 3d) may have led to a peak in volume scattering as shown by a high pedestal height and high cross-pol response (Figure 23c,d). As with canola, which showed a target of random particles, the response plots of 
soybean are also very smooth in comparison to the cereal crops. After harvest, the response returns to surface scattering due to crop residue and soil roughness (Figure 23e,f). Overall, soybean showed very similar response to that of canola, and less so with the three cereal crops.

Figure 21. Oat Cloude-Pottier $\mathrm{H} / \alpha$ decomposition based on RADARSAT-2 fine-quad beam modes for (a) 20 June; (b) 7 August; and (c) 24 September.

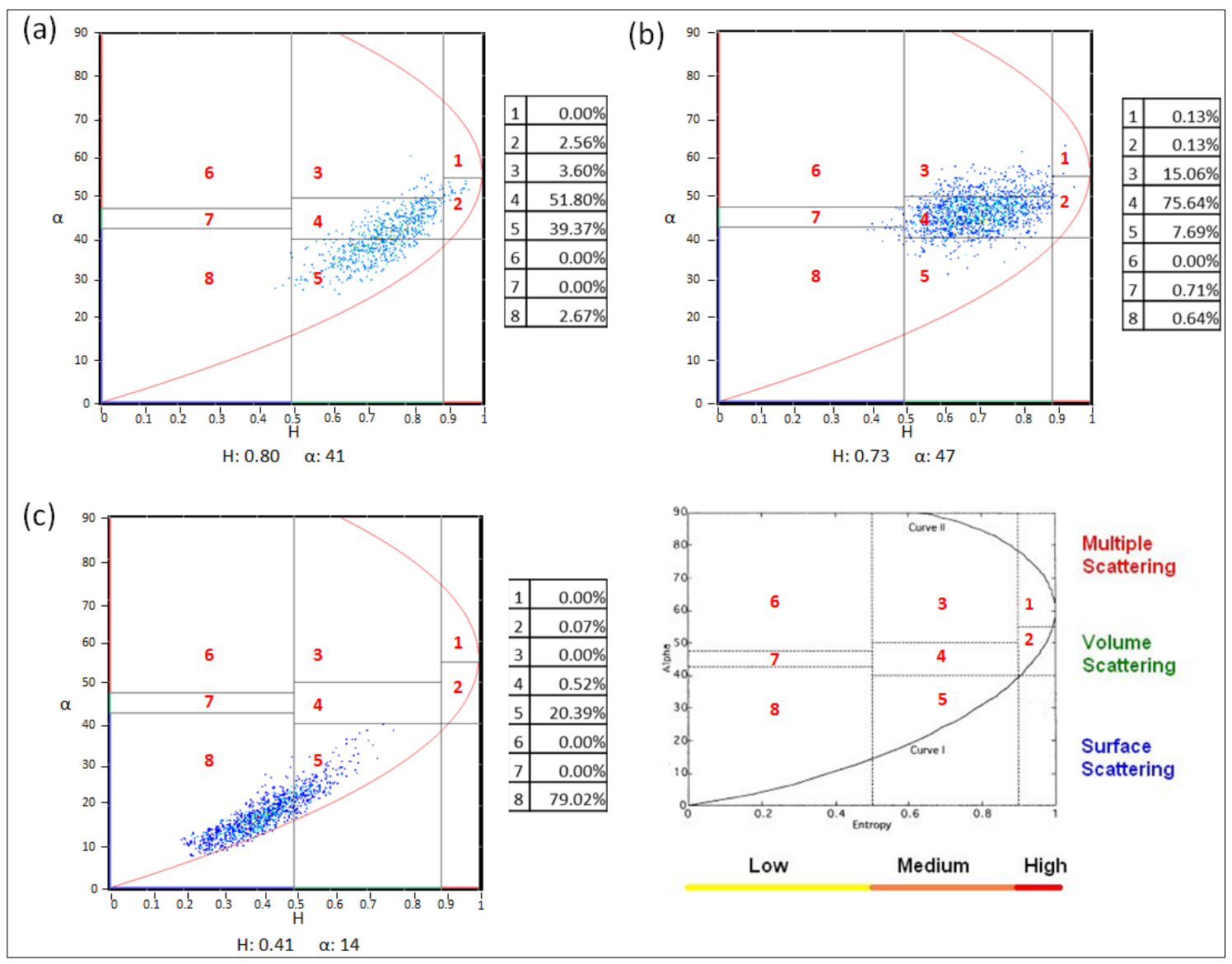

Figure 22. Oat Freeman-Durden decomposition for (a) $41^{\circ}$ and (b) $26^{\circ}$ incidence angles based on RADARSAT-2 fine-quad beam modes. Note that circled days coincide with polarization response plot and Cloude-Pottier decomposition dates; dashed line indicates harvest.

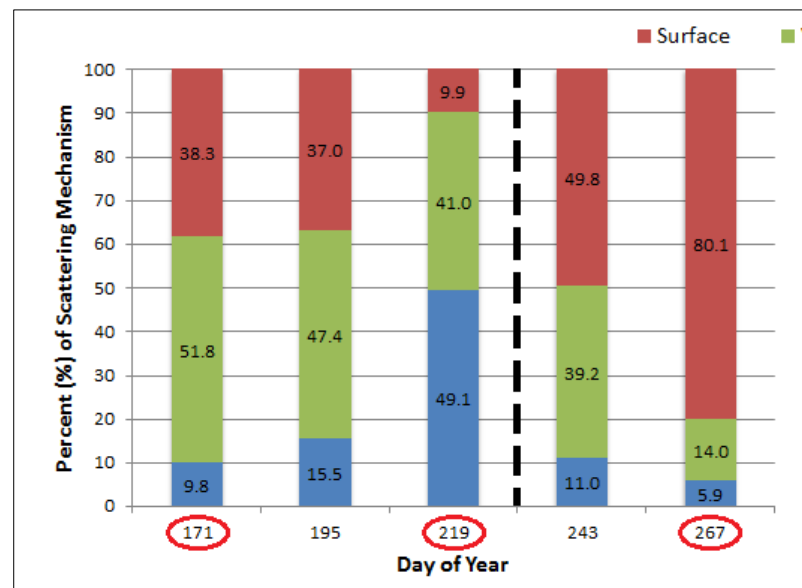

(a)

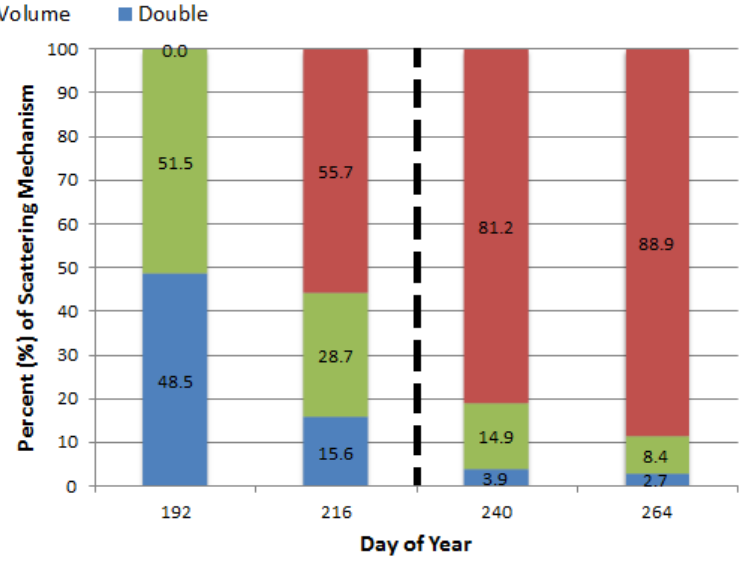

(b) 
Figure 23. Soybean co- (Left) and cross-polarization (Right) polarimetric response plots based on RADARSAT-2 fine-quad beam modes for (a,b) 14 July, (c,d) 28 August, and (e,f) 24 September.

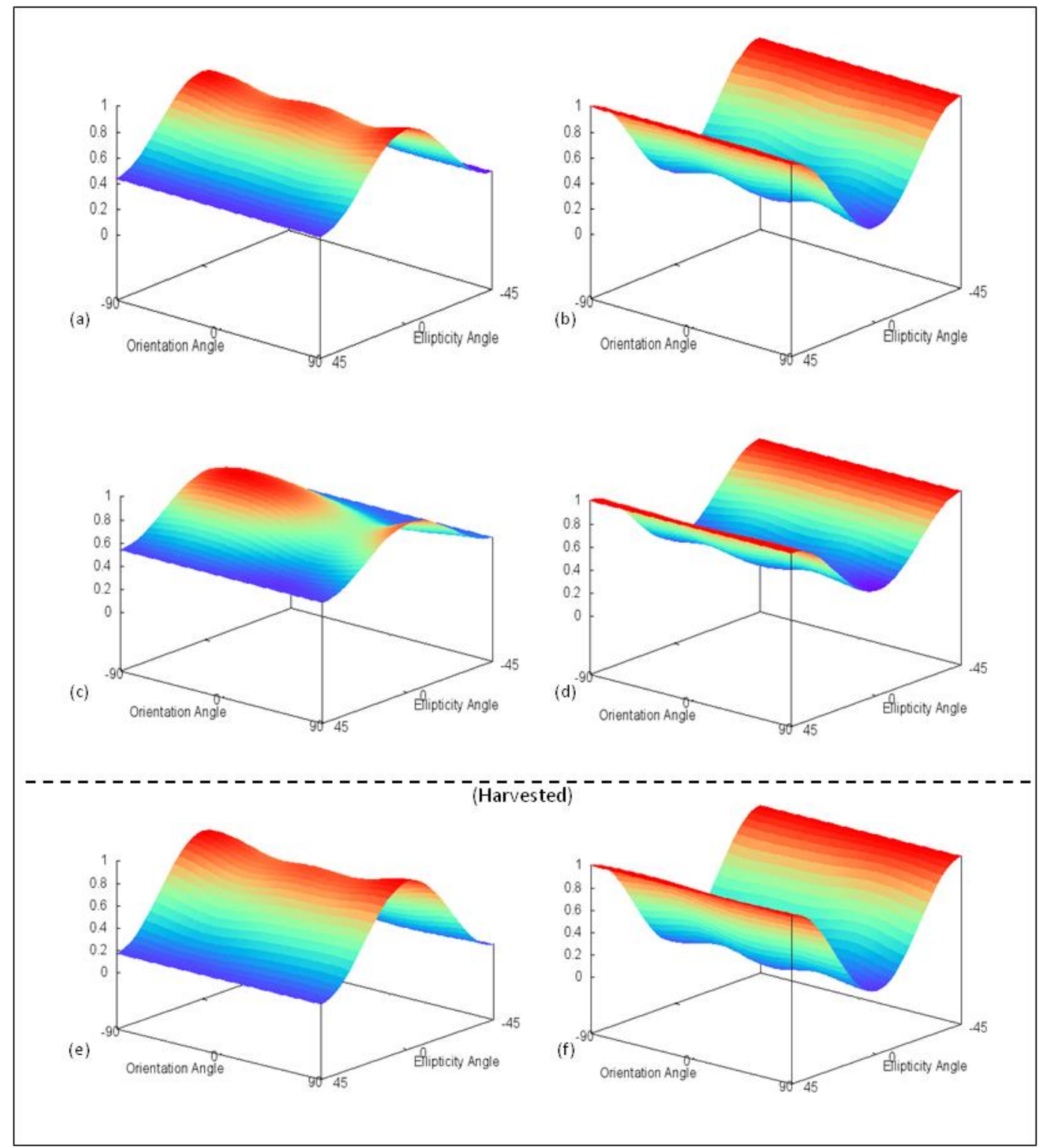

The Cloude-Pottier decompositions also show gradual increase in volume scattering as growth progresses (Figure 24a,b). The shift from zone 5 (surface) in late June (BBCH stage 12) to zone 4 (volume) in August (BBCH stage 87) parallels the changes in response plots as the canopy geometry becomes more complex. Once again, the decomposition returns to zones 5 and 8 once the crop has been harvested, as a result of surface scattering from residue left on the field (Figure 24c). The Freeman-Durden decompositions (Figure 25) display a consistent growth in volume scattering over the course of the summer. As the crop progresses from mid-July (DOY 195) (LAI 3.12) to late August (DOY 243) (LAI 3.93), there is a rise in the volume component. Although the LAI reached its peak in early August (LAI 4.54), the volume scattering had not. This may be due to the absence of the bean pods at this time. Consequently, by DOY 243, the pods had filled and may have greatly influenced the contribution of volume scattering. 
Figure 24. Soybean Cloude-Pottier H/ $\alpha$ decomposition based on RADARSAT-2 fine-quad beam modes for (a) 14 July; (b) 28 August; and (c) 24 September.
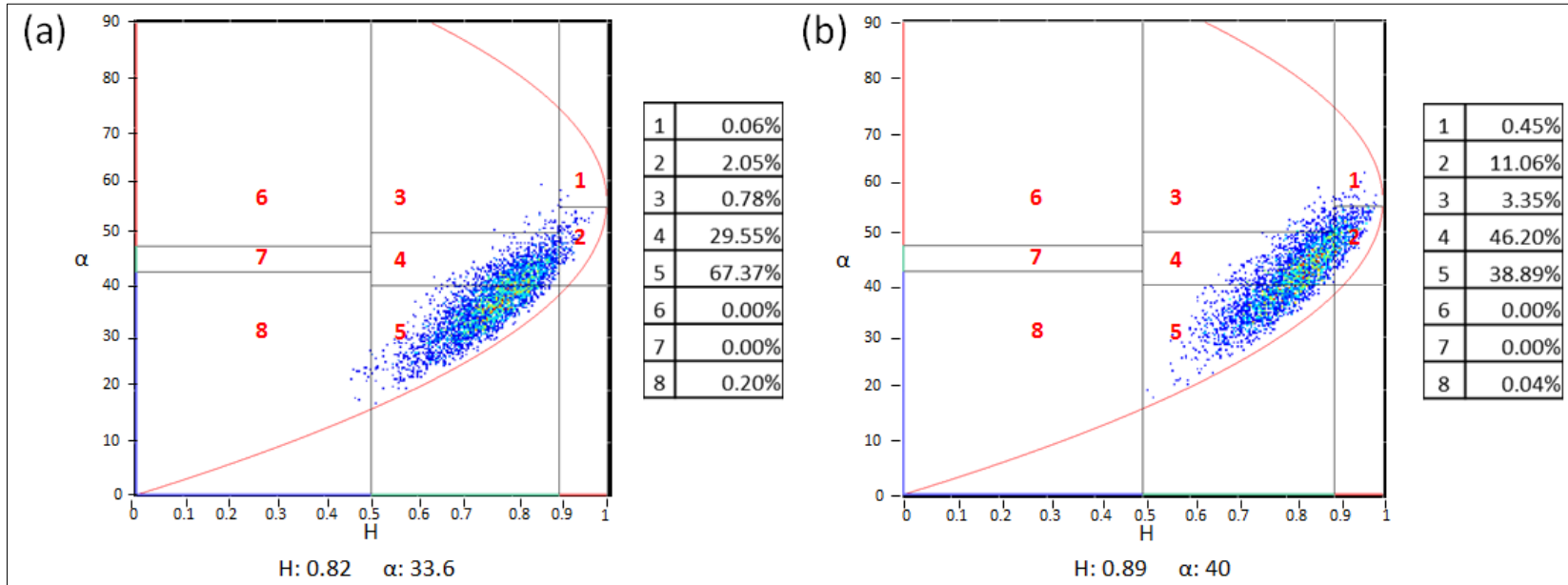

(c)
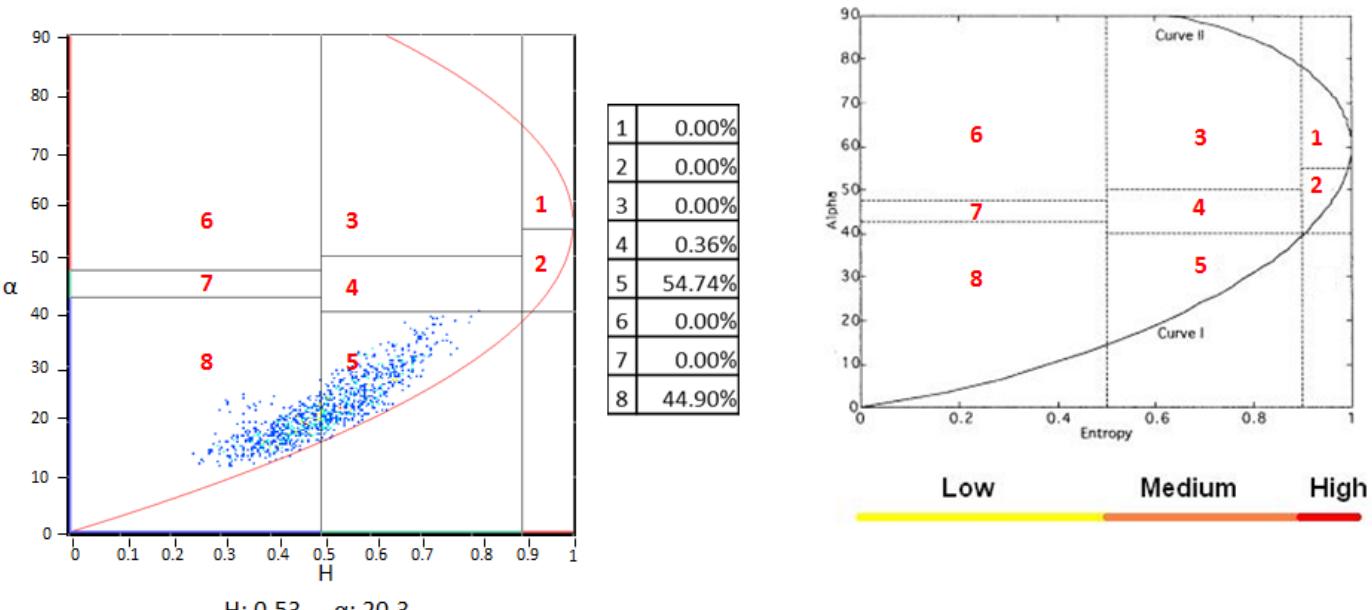

Multiple

Scattering

\begin{tabular}{|l|r|}
\hline 1 & $0.00 \%$ \\
\hline 2 & $0.00 \%$ \\
\hline 3 & $0.00 \%$ \\
\hline 4 & $0.36 \%$ \\
\hline 5 & $54.74 \%$ \\
\hline 6 & $0.00 \%$ \\
\hline 7 & $0.00 \%$ \\
\hline 8 & $44.90 \%$ \\
\hline
\end{tabular}

Volume

Scattering

Surface

Scattering

$H: 0.53 \alpha: 20.3$

Figure 25. Soybean Freeman-Durden decomposition for (a) $41^{\circ}$ and (b) $26^{\circ}$ incidence angles based on RADARSAT-2 fine-quad beam modes. Note that circled days coincide with polarization response plot and Cloude-Pottier decomposition dates; dashed line indicates harvest.

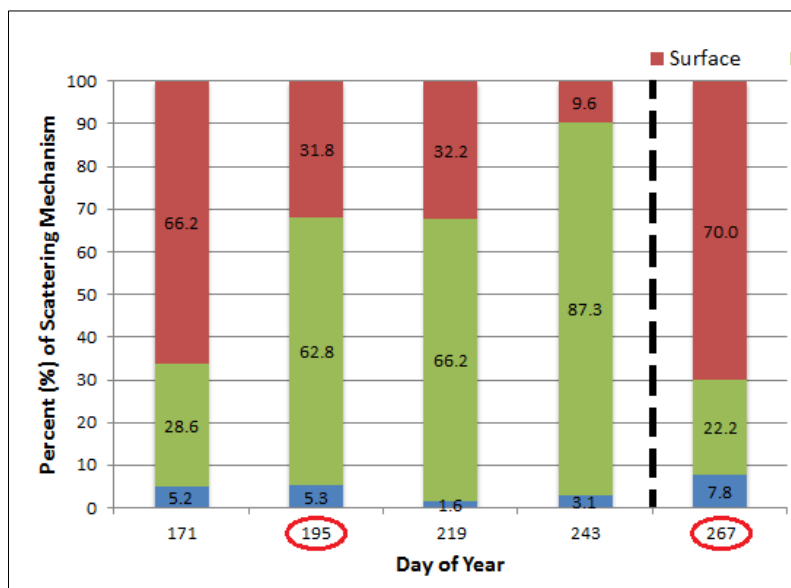

(a)

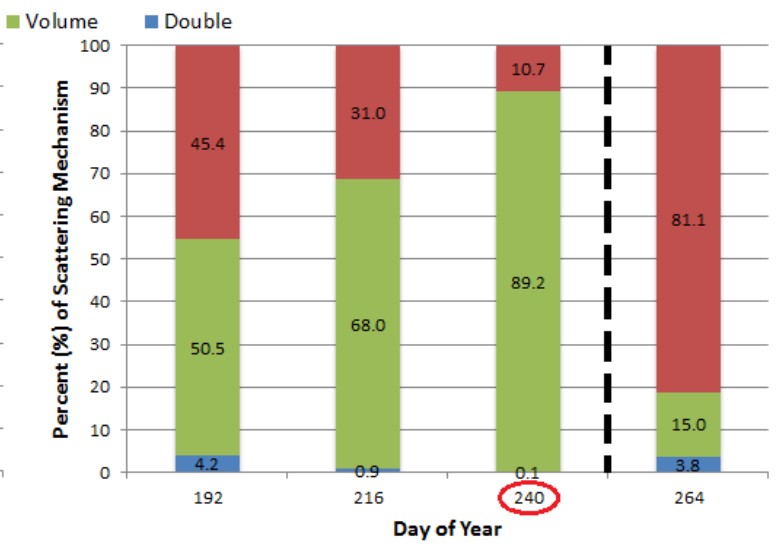

(b) 
Soybean was still reaching maturity during the 31 August acquisition and therefore had not been harvested. Because of the thick canopy present, very little of the signal reached the soil and the backscatter did not show the influence of increased soil moisture following the precipitation event. However, if the precipitation had occurred during or very close to the acquisition, it is expected that the presence of a thin film of water would result in enhanced backscatter. Alternatively, large water droplets or pooling of water would dampen the backscatter signal due to specular reflection.

Figure 26. Wheat co- (Left) and cross-polarization (Right) polarimetric response plots based on RADARSAT-2 fine-quad beam modes for $(\mathbf{a}, \mathbf{b}) 20$ June, (c,d) 14 July, and (e,f) 21 September.

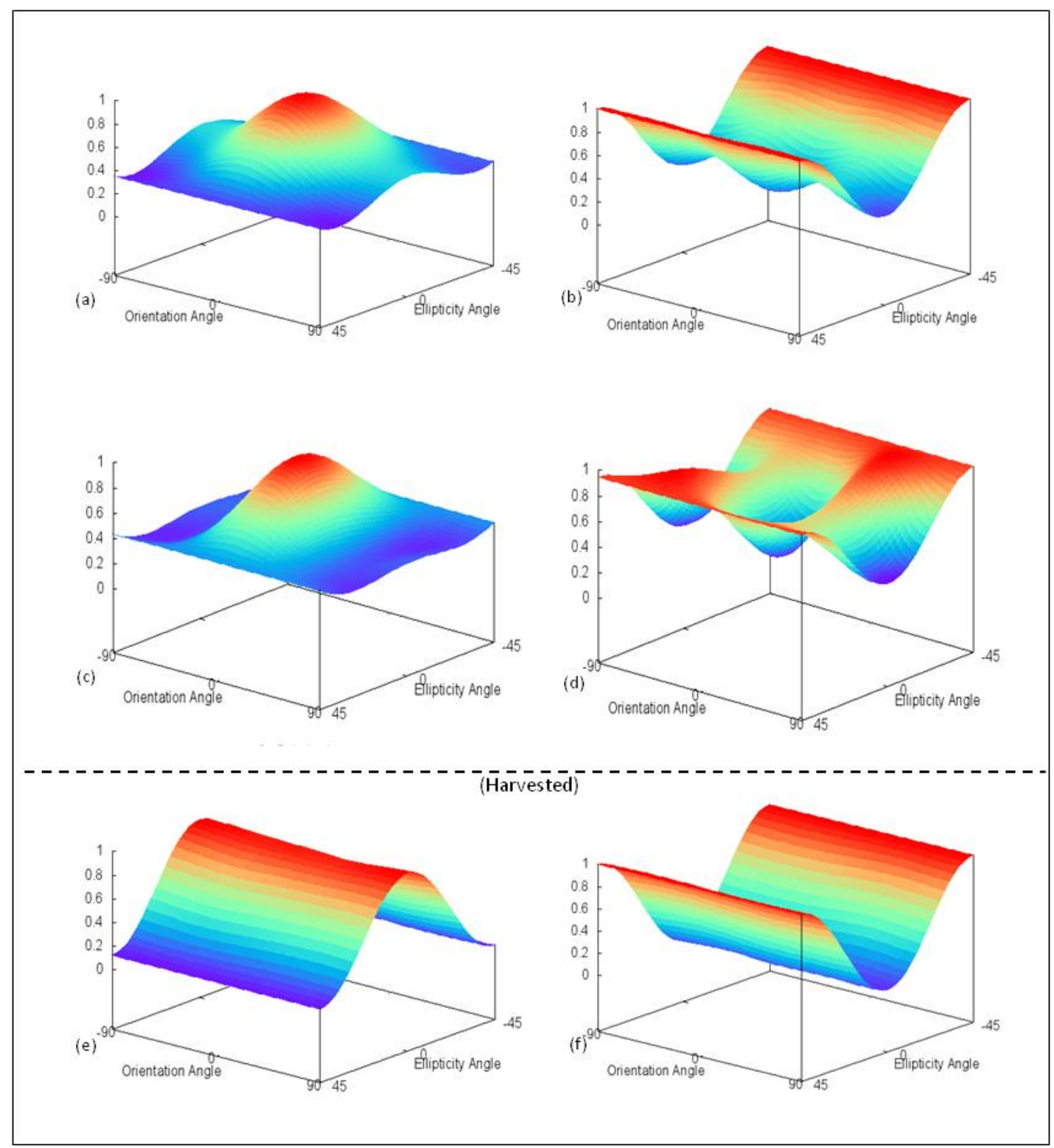

\subsubsection{Wheat}

The results for the wheat were very similar to that of the other two cereal crops. On 20 June (DOY 171), wheat had reached $\mathrm{BBCH}$ stage 33 and a height of $49 \mathrm{~cm}$, leading to a higher $\mathrm{HH}$ response than $\mathrm{VV}$, as well as an increase in volume scattering, indicated by a moderate pedestal height (Figure 26a,b). 
By 14 July (DOY 195), wheat reached BBCH growth stage 65 and a height of $89 \mathrm{~cm}$. This increase in biomass, as indicated by an LAI value of 3.03, lead to the observed increase in both co- and cross-polarized response, as well as a higher pedestal height (Figure 26c,d). The co-polarized responses (Figure 26a,c) shows a stronger $\mathrm{HH}$ response over VV, perhaps indicating the VV energy penetrated between the rows and became de-polarized after scattering off the soil or canopy, or was lost altogether. This could be possible as the look direction of the satellite was parallel with the direction of row orientation of the crop. The post-harvest response plot on 21 September (DOY 264) (Figure 26e,f) exhibited rough surface scattering, and as expected, matched those of McNairn et al. [30].

Figure 27. Wheat Cloude-Pottier H/ $\alpha$ decomposition based on RADARSAT-2 fine-quad beam modes for (a) 20 June; (b) 14 July; and (c) 21 September.
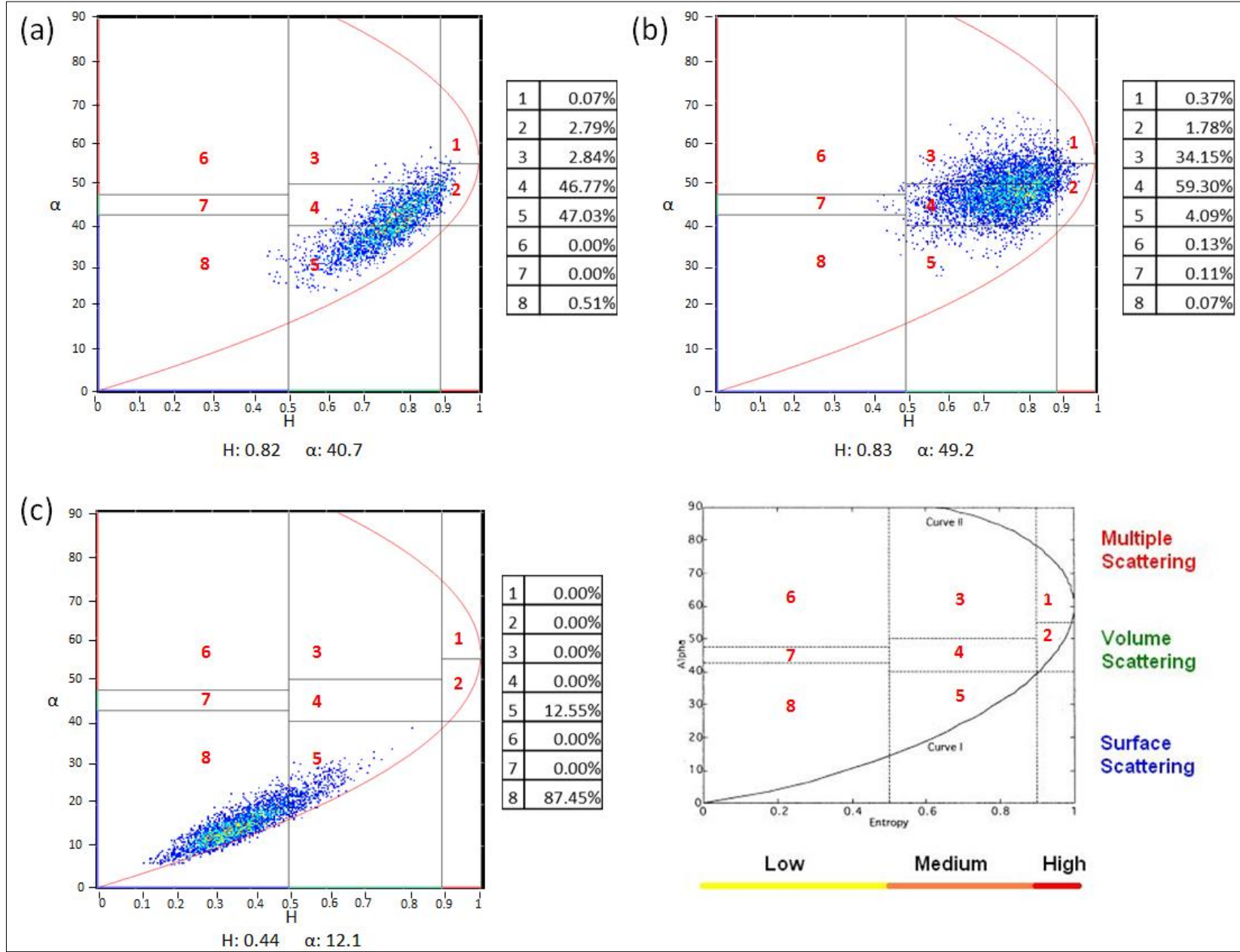

As with the other two cereal crops, the Cloude-Pottier decomposition of wheat for 20 June (Figure 27a) categorizes the majority of the pixels in zones 4 (volume) and 5 (surface), coinciding with the cross-polarized response and pedestal height. The Cloude-Pottier decomposition on 14 July (Figure 27b) shifted to occupy primarily zone 4, further supporting the increased pedestal height and cross-polarized intensity in the response plot that volume scattering is becoming dominant. After the wheat was harvested, the decomposition (Figure 27c) shifts into zone 8 surface scattering. The Freeman-Durden decomposition results for wheat (Figure 28) again resemble the Cloude-Pottier decompositions as well as the response plots. On 20 June, the main scattering component was 
primarily volume scattering. The Freeman-Durden decompositions for wheat also displayed a similar pattern to the other cereal crops as there was a slight rise and fall in double-bounce before reaching maturity. As expected, the Freeman-Durden decomposition of the harvested field (DOY 264) attributes a large component of the signal to surface scattering.

Wheat was also affected by the 31 August rainfall and showed a higher than expected response, entropy and alpha angle for a harvested field. As shown by the Freeman-Durden decomposition (Figure 28), volume scattering was greatly exaggerated on that date due to the rise in soil moisture.

Figure 28. Wheat Freeman-Durden decomposition for (a) $41^{\circ}$ and (b) $26^{\circ}$ incidence angles based on RADARSAT-2 fine-quad beam modes. Note that circled days coincide with polarization response plot and Cloude-Pottier decomposition dates; dashed line indicates harvest.

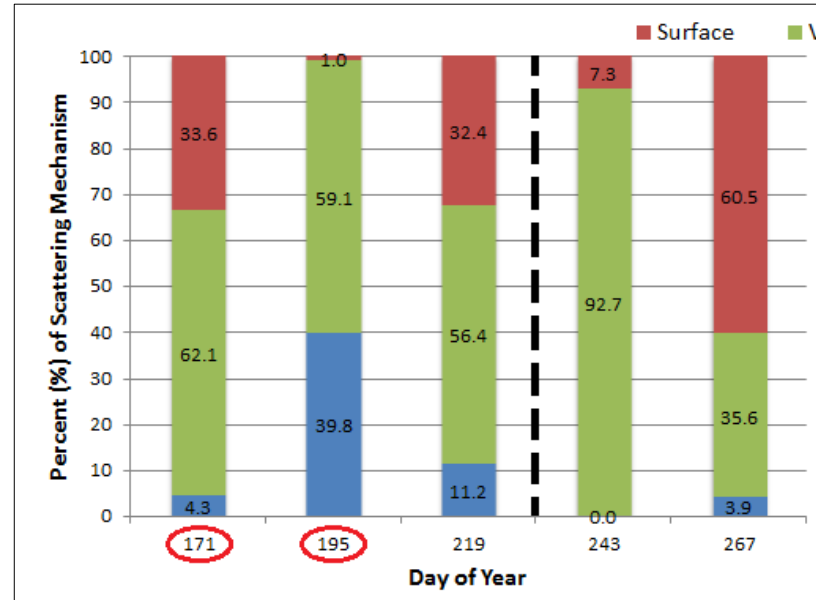

(a)

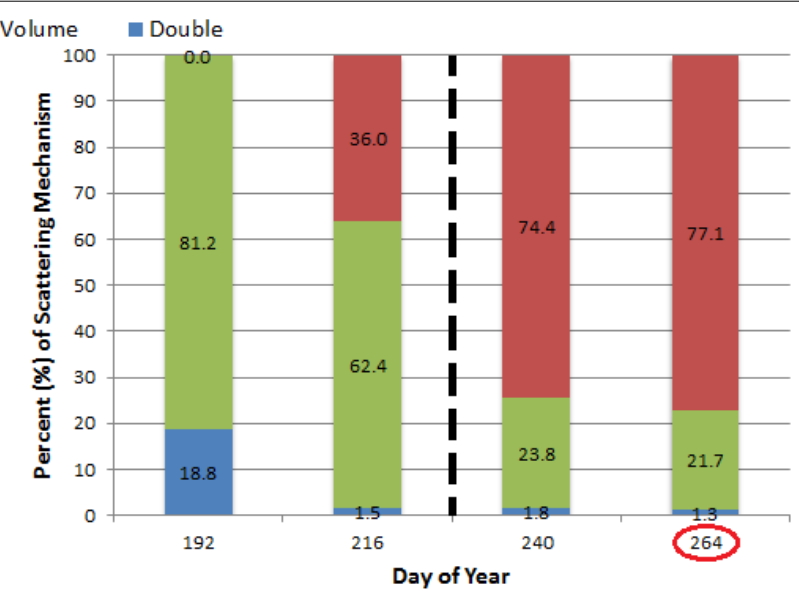

(b)

\section{Conclusions}

The dense canopy targets like soybean and canola displayed higher backscatter values than the cereal crops, yet all backscatter intensities for the crops had a strong relationship with LAI values over the course of the growing season, regardless of incidence angle. However, because the steep angle is much closer to nadir of the target, backscatter values of these acquisitions were slightly higher than those extracted from shallow angle acquisitions where specular reflection is more likely. Co-polarized phase differences were observed for cereal crops possibly due to one of the polarizations penetrating between the rows allowing for double-bounce to occur.

Overall, it is apparent that the cereals (barley, oat and wheat) have lower backscatter responses than either soybean or canola. This may be due to the former crops being thin and planted in definable rows. These characteristics may result in the radar signal penetrating between the rows and deflect away from the sensor. It is also evident that regardless of incidence angle, increased biomass will generate higher backscatter. Canola and soybean create dense canopies leading to higher co- and cross-pol backscatter responses, compared to the cereal crops. Both co- and cross-pol responses diminish at the end of the season for all crops due to the decrease in biomass as the crops senesce and are later harvested.

The Cloude-Pottier decomposition results for each crop target showed a transition from volume scattering at peak growth stages to surface scattering after harvest. These observations were typically 
replicated using the Freeman-Durden decomposition, with a gradual rise and decline of the volume scattering contribution. Cereal crops often displayed a peak in double-bounce scattering at maturity, coinciding with co-polarized phase differences.

While discriminating some crop types using RADARSAT-2 may serve as a challenge (e.g., cereals), the results of this study could be used as a basis for future crop monitoring when comparing the health and status of crops throughout the course of a growing season is required. With the proposed RADARSAT Constellation program, faster revisit times will provide an ability to more closely monitor agricultural productivity, biophysical parameters (e.g., LAI, crop height) and possibly identifying crop damage or defoliation due to disease, insect infestation or storm events. Moreover, given the frequent cloud cover for the region during the growing season, SAR data could provide accurate results regardless of atmospheric conditions. Although not as common in Northern Ontario, the production of white bean (Phaseolus vulgaris), flax (Linum usitatissimum) and corn (Zea mays) are becoming a viable option to local producers. Consequently, polarimetric target analysis of these cash crops may be considered. Additionally, the analysis of polarimetric properties of land use/land covers using shorter radar wavelengths, such X-band, or longer wavelengths like L-band, could provide additional information for improved monitoring and insight into crop condition.

\section{Acknowledgments}

We would like to thank Jeffrey $\mathrm{H}$. Wilson for his assistance with in-field data collection. Additional thanks to Mark Wachowiak of Nipissing University, Steven Roberge of Ferme Roberge and all members of the West Nipissing branch of the Ontario Soil and Crop Improvement Association for their support during this investigation. Funding was provided through a grant from the Northern Ontario Heritage Fund Corporation of Canada (project \# 920161). Finally, we would like to thank the three anonymous reviewers for their comments and suggestions.

\section{Authors Contributions}

Jeffrey W. Cable is the principal author of this manuscript having written the majority of the manuscript and contributing at all phases of the investigation. The other co-authors contributed in the field logistics, the field design, the selection and interpretation of the methods and contributed some portions of the written manuscript. The order of the authors reflects their level of contribution.

\section{Conflicts of Interest}

The authors declare no conflict of interest.

\section{References}

1. Kittson, K. An Overview of the Canadian Agriculture and Agri-Food System; Research and Analysis Directorate, Stategic Policy Branch, Agriculture and Agri-Food Canada: Ottawa, ON, Canada, 2013.

2. Skriver, H.; Svendsen, M.T.; Thomsen, A.G. Multitemporal C- and L-band polarimetric signatures of crops. IEEE Trans. Geosci. Remote Sens. 1999, 37, 2413-2429. 
3. McNairn, H.; Hochheim, K.; Rabe, N. Applying polarimetric radar imagery for mapping the productivity of wheat crops. Can. J. Remote Sens. 2004, 30, 517-524.

4. Soria-Ruiz, J.; McNairn, H.; Fernandez-Ordonez, Y.; Bugden-Storie, J. Corn Monitoring and Crop Yield Using Optical and RADARSAT-2 Images. In Proceedings of the 2009 IEEE Geoscience and Remote Sensing Symposium (IGARSS), Barcelona, Spain, 23-28 July 2007.

5. Wang, D.; Lin, H.; Chen, J.; Zhang, Y.; Zeng, Q. Application of multi-temporal ENVISAT ASAR data to agricultural area mapping in the Pearl River Delta. Int. J. Remote Sens. 2010, 31, $1555-1572$.

6. Kim, Y.; Jackson, T.; Bindlish, R.; Lee, H.; Hong, S. Monitoring soybean growth using L-, C- and X-band scatterometer data. Int. J. Remote Sens. 2013, 34, 4069-4082.

7. Adams, J.R.; Rowlandson, T.L.; McKeown, S.J.; Berg, A.A.; McNairn, H.; Sweeny, S.J. Evaluating the Cloude-Pottier and Freeman-Durden scattering decompositions for distinguishing between unharvested and post-harvested agricultural fields. Can. J. Remote Sens. 2013, 39, 1-10.

8. Brisco, B.; Brown, R.J. Agricultural Applications with Radar. In Manual of Remote Sensing: Principles and Applications of Imaging Radar, 3rd ed.; Henderson, F.M., Lewis, A.J., Eds.; John Wiley and Sons: Toronto, Canada, 1998; Volume 2, pp. 381-406.

9. Kim, Y.; van Zyl, J.J. A time-series approach to estimate soil moisture using polarimetric radar data. IEEE Trans. Geosci. Remote Sens. 2009, 47, 2519-2527.

10. McNairn, H.; Duguay, C.; Brisco, B.; Pultz, T.J. The effect of soil and crop residue characteristics on polarimetric radar response. Remote Sens. Environ. 2002, 80, 308-320.

11. Ulaby, F.T.; Held, D.; Dobson, M.C.; McDonald, K.C.; Senior, T.B.A. Relating polarization phase difference of SAR signals to scene properties. IEEE Trans. Geosci. Remote Sens. 1987, 25, 83-92.

12. Shang, J.; McNairn, H.; Deschamps, J.; Jiao, X. In-season crop inventory using multi-angle and multi-pass RADARSAT-2 SAR data over the Canadian prairies. Proc. SPIE 2011, doi:10.1117/12.894211.

13. Vaglio Laurin, G.; Del Frate, F.; Pasolli, L.; Notarnicola, C.; Guerriero, L.; Valentini, R. Discrimination of vegetation types in alpine sites with ALOS PALSAR-, RADARSAT-2- and lidar-derived information. Int. J. Remote Sens. 2013, 34, 6898-6913.

14. McNairn, H.; Shang, J.; Champagne, C.; Jiao, X. TERRASAR-X and RADARSAT-2 for Crop Classification and Acreage Estimation. In Proceedings of the 2009 IEEE International Geoscience and Remote Sensing Symposium (IGARSS), Cape Town, South Africa, 12-17 July 2009.

15. Liu, C.; Shang, J.; Vachon, P.W.; McNairn, H. Multiyear crop monitoring using polarimetric RADARSAT-2 data. IEEE Trans. Geosci. Remote Sens. 2013, 51, 2227-2240.

16. Cable, J.W.; Kovacs, J.M.; Shang, J.; Jiao, X. Multi-temporal polarimetric RADARSAT-2 for land cover monitoring in Northeastern Ontario, Canada. Remote Sens. 2014, in press.

17. Webber, L.R.; Hoffman, D.W. Origin, Classification and Use of Ontario Soils; Ontario Department of Agriculture and Food: Toronto, ON, Canada, 1970; p. 58.

18. Baldwin, D.J.B.; Desloges, J.R.; Band, L.E. Physical Geography of Ontario. In Ecology of a Managed Terrestrial Landscape: Patterns and Processes of Forest Landscapes in Ontario; Perera, A.H., Euler, D.E., Thompson, I.D., Eds.; University of British Columbia Press: Vancouver, BC, Canada, 2000; pp. 141-162. 
19. The Corporation of the Municipality of West Nipissing. Agriculture in West Nipissing. Available online: http://www.westnipissingouest.ca/agriculture.html (accessed on 26 April 2012).

20. Decagon Devices. AccuPAR LP-80. Available online: http://www.decagon.com/products/ environmental-instruments/ceptometer-par-lai-instruments-2/accupar-lp-80/ (accessed on 15 June 2013).

21. Jiao, X.; McNairn, H.; Shang, J.; Pattey, E.; Liu, J.; Champagne, C. The sensitivity of RADARSAT-2 polarimetric SAR data to corn and soybean leaf area index (LAI). Can. J. Remote Sens. 2011, 37, 69-81.

22. Li, K.; Brisco, B.; Yun, S. Polarimetric decomposition with RADARSAT-2 for rice mapping and monitoring. Can. J. Remote Sens. 2012, 38, 169-179.

23. Lee, J.S.; Pottier, E. Polarimetric Radar Imaging; CRC Press: Boca Raton, FL, USA, 2009; p. 398.

24. Boerner, W.M.; Mott, H.; Luneburg, E.; Livingstone, C.; Brisco, B.; Brown, R.J.; Patterson, J.S. Polarimetry in Radar Remote Sensing: Basic and Applied Concepts. In Manual of Remote Sensing: Principles and Applications of Imaging Radar, 3rd ed.; Henderson, F.M., Lewis, A.J., Eds.; John Wiley and Sons: Toronto, ON, Canada, 1998; Volume 2, pp. 271-356.

25. Van Zyl, J.J.; Zebker, H.A.; Elachi, C. Imaging radar polarization signatures: Theory and observations. Radio Sci. 1987, 22, 529-543.

26. Cloude, S.R.; Pottier, E. An entropy classificationscheme for land applications of polarimetric SAR data. IEEE Trans. Geosci. Remote Sens. 1997, 35, 68-78.

27. Freeman, A.; Durden, S.L. A three-component scattering model for polarimetric SAR data. IEEE Trans. Geosci. Remote Sens. 1998, 36, 963-973.

28. Van Zyl, J.J.; Zebker, H.A. Imaging Radar Polarimetry. In Progress in Electromagnetics Research 3: Polarimetric Remote Sensing; Kong, J.A., Ed.; Elsevier: New York, NY, USA, 1990; pp. 277-326.

29. Baghdadi, N.; Cresson, R.; Pottier, E.; Aubert, M.; Zribi, M.; Jacome, A.; Benabdallah, S. A potential use for the C-band polarimetric SAR parameters to characterize the soil surface over bare agricultural fields. IEEE Trans. Geosci. Remote Sens. 2012, 50, 3844-3858.

30. McNairn, H.; Shang, J.; Jiao, X.; Champagne, C. The contribution of ALOS PALSAR multipolarization and polarimetric data to crop classification. IEEE Trans. Geosci. Remote Sens. 2009, 47, 3981-3992.

(C) 2014 by the authors; licensee MDPI, Basel, Switzerland. This article is an open access article distributed under the terms and conditions of the Creative Commons Attribution license (http://creativecommons.org/licenses/by/3.0/). 